\title{
The interaction between stress and chronic pain through the lens of threat learning
}

Citation for published version (APA):

Timmers, I., Quaedflieg, C. W. E. M., Hsu, C., Heathcote, L. C., Rovnaghi, C. R., \& Simons, L. E. (2019). The interaction between stress and chronic pain through the lens of threat learning. Neuroscience and Biobehavioral Reviews, 107, 641-655. https://doi.org/10.1016/j.neubiorev.2019.10.007

Document status and date:

Published: 01/12/2019

DOI:

10.1016/j.neubiorev.2019.10.007

Document Version:

Publisher's PDF, also known as Version of record

Document license:

Taverne

Please check the document version of this publication:

- A submitted manuscript is the version of the article upon submission and before peer-review. There can be important differences between the submitted version and the official published version of record.

People interested in the research are advised to contact the author for the final version of the publication, or visit the DOI to the publisher's website.

- The final author version and the galley proof are versions of the publication after peer review.

- The final published version features the final layout of the paper including the volume, issue and page numbers.

Link to publication

\footnotetext{
General rights rights.

- You may freely distribute the URL identifying the publication in the public portal. please follow below link for the End User Agreement:

www.umlib.nl/taverne-license

Take down policy

If you believe that this document breaches copyright please contact us at:

repository@maastrichtuniversity.nl

providing details and we will investigate your claim.
}

Copyright and moral rights for the publications made accessible in the public portal are retained by the authors and/or other copyright owners and it is a condition of accessing publications that users recognise and abide by the legal requirements associated with these

- Users may download and print one copy of any publication from the public portal for the purpose of private study or research.

- You may not further distribute the material or use it for any profit-making activity or commercial gain

If the publication is distributed under the terms of Article $25 \mathrm{fa}$ of the Dutch Copyright Act, indicated by the "Taverne" license above, 
Review article

\title{
The interaction between stress and chronic pain through the lens of threat learning
}

\author{
Inge Timmers ${ }^{\mathrm{a}}{ }_{*}$, Conny W.E.M. Quaedflieg ${ }^{\mathrm{b}}$, Connie Hsu ${ }^{\mathrm{c}}$, Lauren C. Heathcote ${ }^{\mathrm{a}}$, \\ Cynthia R. Rovnaghi ${ }^{\mathrm{d}}$, Laura E. Simons ${ }^{\mathrm{a}}$ \\ ${ }^{a}$ Department of Anesthesiology, Perioperative, and Pain Medicine, Stanford University School of Medicine, 1070 Arastradero Road, Suite 300, Palo Alto, CA 94304, \\ United States \\ ${ }^{\mathrm{b}}$ Department of Clinical Psychological Science, Maastricht University, P.O. Box 616, 6200 MD Maastricht, The Netherlands \\ ${ }^{\mathrm{c}}$ Feinberg School of Medicine, Northwestern University, 420 E Superior St, Chicago, IL 60611, United States \\ ${ }^{\mathrm{d}}$ Department of Pediatrics, Stanford University School of Medicine, 770 Welch Road, Suite 435, Stanford, CA 94304, United States
}

A R T I C L E I N F O

\section{Keywords:}

Chronic pain

HPA axis

Stress

Cortisol

Learning and memory

Threat learning

Fear avoidance model

Pain

\begin{abstract}
A B S T R A C T
Stress and pain are interleaved at multiple levels - interacting and influencing each other. Both are modulated by psychosocial factors including fears, beliefs, and goals, and are served by overlapping neural substrates. One major contributing factor in the development and maintenance of chronic pain is threat learning, with pain as an emotionally-salient threat - or stressor. Here, we argue that threat learning is a central mechanism and contributor, mediating the relationship between stress and chronic pain. We review the state of the art on (mal) adaptive learning in chronic pain, and on effects of stress and particularly cortisol on learning. We then provide a theoretical integration of how stress may affect chronic pain through its effect on threat learning. Prolonged stress, as may be experienced by patients with chronic pain, and its resulting changes in key brain networks modulating stress responses and threat learning, may further exacerbate these impairing effects on threat learning. We provide testable hypotheses and suggestions for how this integration may guide future research and clinical approaches in chronic pain.
\end{abstract}

\section{Introduction}

Stress and pain are interleaved at multiple levels. Acute stress and acute pain often co-occur and are known to influence each other. Acute stress can affect sensitivity to experimentally-delivered noxious stimuli resulting in both increased or decreased pain experiences (see e.g., al'Absi and Petersen, 2003; Caceres and Burns, 1997; Crettaz et al., 2013; Timmers et al., 2018). Acute stress can also exacerbate pain intensity in the context of chronic pain (Fischer et al., 2016). Pain -whether acute or chronic- can also be a powerful systemic stressor. Pain can activate the body's major stress response system, the hypothalamic-pituitary-adrenal (HPA) axis, to release the stress hormone cortisol (Ulrich-Lai and Herman, 2009). When stress is prolonged (chronic), the HPA axis can become dysregulated, resulting in either a hypo- or hyperactive system (Miller et al., 2007). This wear-and-tear from overuse of the system is also called allostatic load, which is characterized by nervous system dysregulation and is associated with disease (McEwen, 1998, 2008), including the development of chronic pain (Borsook et al., 2012; Chapman et al., 2008; Woda et al., 2016). In patients with chronic pain, dysfunction of the HPA axis is evidenced by both increases and decreases in basal cortisol levels as well as elevated and flattened cortisol reactivity (see Woda et al., 2016, for an overview). Thus, there is evidence for dynamic interactions between pain and stress at both the acute and chronic level. In this narrative review, we posit that threat learning is a central mechanism and major contributor to this dynamic relationship between stress and pain, and acts as a mediator in this relation. Our main aim is to comprehensively consider the interaction between stress and pain through the lens of threat learning, thus considering how threat learning may play a vital role in explaining this complex interaction.

Beyond their direct interactions, both stress and pain are jointly modulated by psychosocial factors such as fears, beliefs, goals, and the social context (Dickerson and Kemeny, 2004; Karos et al., 2018; Kudielka et al., 2009; Simons et al., 2014a). This is in line with the striking overlap in brain networks associated with the modulation of chronic stress and chronic pain (Vachon-Presseau, 2018; overlap is highlighted in Fig. 1). The corticolimbic system, including the amygdala, hippocampus, and medial prefrontal cortex (mPFC), and the

\footnotetext{
* Corresponding author.

E-mail address: itimmers@stanford.edu (I. Timmers).
} 


\section{A. Factors influencing pain experience}

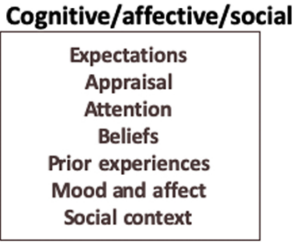

\section{Behavioral}

Pain avoidance Safety behavio

\begin{tabular}{|c|}
\hline Biological \\
\hline Stress responses \\
Chemical function (e.g., \\
opioid/catecholamine \\
signaling) \\
Reward processing \\
Genetics
\end{tabular}

\section{B. Brain areas implicated in (chronic) pain}

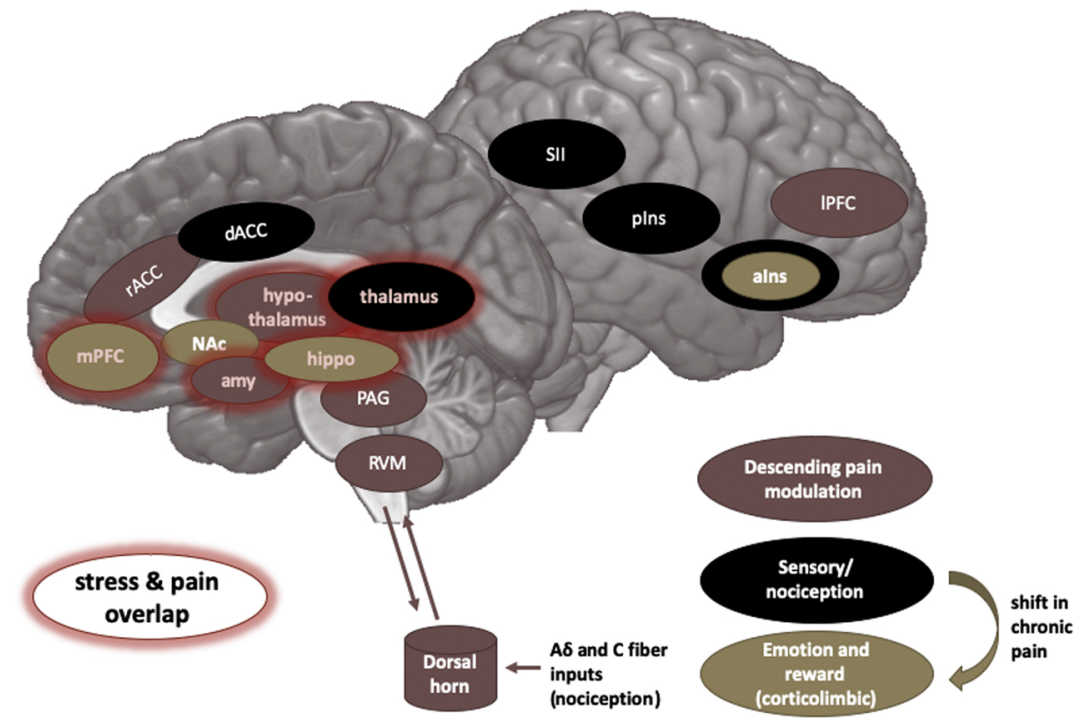

Fig. 1. Pain and its modulation. A. Factors that are known to influence the pain experience are listed. B. The main brain areas/networks implicated in pain and chronic pain. Brain areas overlapping with stress responses are highlighted in red. a/pIns = anterior/posterior insula, amy $=$ amygdala, $d / r A C C=$ dorsal/rostral anterior cingulate cortex, hippo $=$ hippocampus, $1 / \mathrm{mPFC}=$ lateral $/$ medial prefrontal cortex, $\mathrm{NAc}=$ nucleus accumbens, OFC $=$ orbitofrontal cortex, PAG $=$ periaqueductal grey, $\mathrm{RVM}=$ rostral ventromedial medulla, $\mathrm{SI} / \mathrm{SII}=$ primary/secondary somatosensory cortex.

thalamus are key regions associated with the endocrine stress response (Ulrich-Lai and Herman, 2009; van Oort et al., 2017) and with pain persistence. Moreover, the deleterious psychological effects of chronic stress are similar to those of chronic pain, including increased depressive symptoms, increased anxiety, and impaired learning and memory (Hannibal and Bishop, 2014; Nees and Becker, 2018; Radley et al., 2015; Simons et al., 2014a).

Chronic pain is defined as pain lasting longer than the expected healing period, which is often practically defined as pain lasting longer than three to six months (definitions vary across clinical and research contexts). As opposed to acute pain, chronic pain is no longer adaptive. It has been considered to stem from a 'faulty alarm system' - activating the body's physiological systems inappropriately, when there is no acute threat. Of note, here we predominantly refer to non-disease-related chronic pain, recently defined as chronic primary pain in the ICD11 classification (Nicholas et al., 2019). In line with brain changes, maladaptive pain-related cognitions (e.g., catastrophizing) and fears are major contributing factors for the development and maintenance of chronic pain for a subset of patients, as is described in the fear avoidance model of chronic pain (Vlaeyen et al., 2016, 1995b). Pain-related fears are acquired through both classical (Pavlovian) and operant learning mechanisms, and there is evidence that this threat-safety discrimination learning is impaired and/or excessive in patients with chronic pain (Harvie et al., 2017). Threat-safety discrimination refers to learning to associate certain movements/activities/cues with threat, while learning to associate others with safety, hence serving an important protective function for all organisms. There is also emerging evidence that pain catastrophizing and pain-related fear, sometimes collectively referred to as pain-related distress, are key to explaining some of the observed differences in chronic pain. For instance, in a recent study, we only observed altered self-reported and neural correlates of threat learning in patients with chronic pain and high painrelated distress, but not in patients with chronic pain and low painrelated distress (Heathcote et al., under review). Interestingly, acute stress, via the secretion of cortisol, has a pronounced effect on learning of emotionally salient stimuli. Specifically, acute stress biases our system towards encoding and consolidation of the threat memory, at the expense of other important functions including the updating of memory traces (Raio et al., 2017) and flexible goal-directed behavior
(Hermans et al., 2014; Quaedflieg and Schwabe, 2018). In turn, these biases further add to the vicious cycle as described in the fear avoidance model of chronic pain.

Interactions between stress and (chronic) pain have been reviewed before (see e.g., Abdallah and Geha, 2017; Woda et al., 2016). However, their mutual relation with threat learning is often overlooked, limited to one type of learning (see e.g., Elsenbruch and Wolf, 2015, focusing on classical conditioning) or limited to their neural underpinnings (Vachon-Presseau, 2018). The main aim of this review is therefore to comprehensively consider the interaction between stress and pain through the lens of threat learning. When a stimulus is considered a threat, our system is primed to learn about and adapt our behavior according to that threat, aided by our stress response systems. In this narrative review, we focus on the roles of the HPA axis and its major stress hormone cortisol. We will start with laying out a guiding model of how we propose threat processing and learning interacts with the HPA axis stress response system and (chronic) pain, continue with introducing the key concepts and the effects of stress on (chronic) pain, and vice versa, and then delve into the relation between stress, pain, and threat learning deeper. After the theoretical integration, we provide testable hypotheses for this model, and provide suggestions for how this integration can guide future research and clinical approaches in chronic pain.

\section{Key model and key concepts: (chronic) pain and stress}

\subsection{The model}

The central role of pain-related distress in the development and maintenance of chronic pain is clearly described in the fear avoidance model, as is the importance of processing the threat value of a potentially harmful stimulus and the subsequent learning about that threat. Here, we argue that threat processing and learning is a central mechanism and major contributor to the relationship between stress and pain, acting as a mediator. We will lay out the most important points of contact for stress in its interaction with threat learning and (chronic) pain, providing a guiding thread throughout the review. In particular, we argue that several factors, including a stress response, can bias our system to more likely perceive a potentially harmful stimulus or 


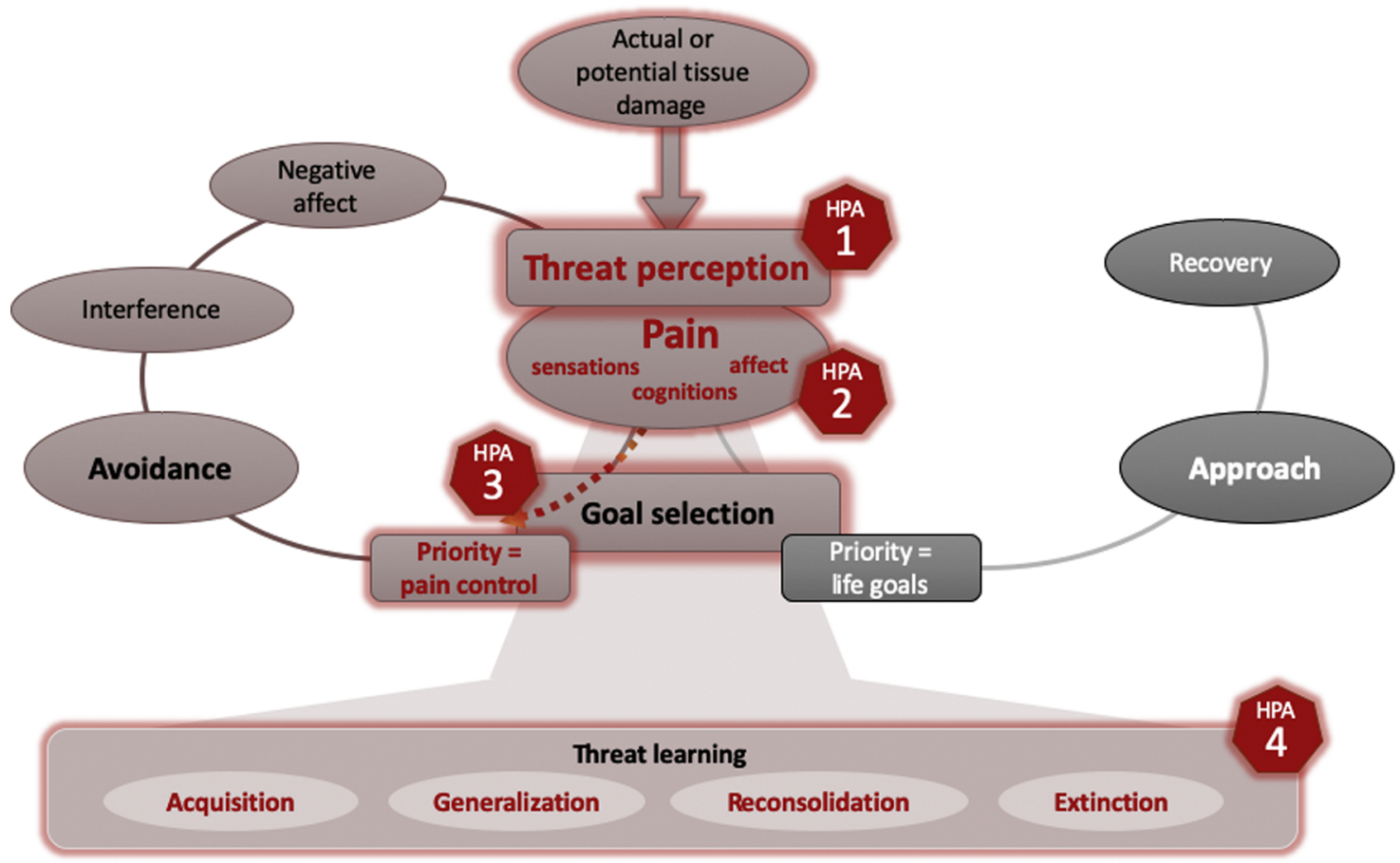

Fig. 2. Proposed key points of contact for stress, overlaid on an adapted version of the fear avoidance model of chronic pain. The four points of contact where the HPA axis stress response is argued to interact with threat learning and pain are: [1] Stress may bias our system into perceiving a stimulus or situation with actual or potential tissue damage as highly threatening by increasing attention to the threat and optimizing threat-processing. [2] Pain-related distress (e.g., catastrophizing, fears) may facilitate the activation of the HPA axis stress response, while an HPA axis stress response may also affect aspects of the pain experience. [3] Stress may bias towards inflexible, rule-governed behavior by compromising value-based, flexible goal-directed behavior. [4] Stress may further modulate threat learning. Fear avoidance model adapted from Vlaeyen et al. (2016).

situation as a highly threatening [1]. Also, we posit that increased painrelated distress (e.g., catastrophic cognitions, worries, fears) may facilitate activation of the HPA axis, while an HPA axis stress response may also affect certain aspects of the pain experience (e.g., sensory pain thresholds) [2]. Stress furthermore compromises values-based, flexible goal-directed behavior in favor of more habit-like, inflexible behavior that focuses on pain control [3]. When pain is perceived as a high threat and immediate pain control is prioritized, stress further affects threat learning by facilitating acquisition, generalization and reconsolidation of the threat memory, while also modulating extinction [4]. Fig. 2 presents an overview of these proposed interactions, overlaid on the fear avoidance model of chronic pain.

\subsection{Pain and its modulation by threat}

Pain is defined as "a distressing experience associated with actual or potential tissue damage with sensory, emotional, cognitive and social components" (Williams and Craig, 2016; and a new definition by International Association for the Study of Pain is announced, August 2019). Nociception refers to the neural process of encoding noxious stimuli (i.e., a stimulus that is damaging or threatens damage to normal tissues; definition from International Association for the Study of Pain; iasp-pain.org/terminology). This multifaceted experience is reflected in the complex network of brain regions that have been implicated in the processing of pain and/or nociception (Garcia-Larrea and Peyron, 2013; Schweinhardt and Bushnell, 2010; Wager et al., 2013), as displayed in Fig. 1. Importantly, not all nociceptive signals will lead to the experience of pain, and not all pain experiences involve a nociceptive signal. Our prior experiences, our expectations, and the individual and social context can dramatically modulate the perception of noxious or innocuous stimuli via our brain's descending pain modulatory system. This descending modulatory system involves several (sub)cortical regions that connect to brainstem regions to either amplify or inhibit the pain response. This modulation depends on psychosocial factors such as our expectations, (threat) appraisals, and mood (Arntz and Claassens, 2004; Lopez-Sola et al., 2018; Villemure and Bushnell, 2002). Regarding expectations, numerous studies have demonstrated the powerful pain modulatory effect of placebo -and its counterpart nocebo- on pain processing (Buchel et al., 2014; Tracey, 2010). Moreover, early work demonstrated that anticipatory anxiety (i.e., the anticipation of threat) can exacerbate pain intensity via engagement of the hippocampal complex (Ploghaus et al., 2001), suggesting involvement of the memory system.

\subsection{Chronification of pain in face of perceived threat}

In the acute phase, pain functions as an alarm system. In this phase, it is adaptive to learn to avoid situations that cause harm (e.g., bearing weight on a broken foot). When pain becomes chronic (e.g., the fracture is healed, but pain persists), it is no longer adaptive to avoid weight bearing on that foot. Fear towards situations that are associated with pain may become excessive, may generalize to other situations and may result in avoiding these situations in a way that interferes with daily functioning (e.g., no longer walking or biking to work, not joining friends to a festival). It is proposed that the cognitive, affective, and social components of pain processing are particularly altered in chronic pain. Pain-related fear, pain catastrophizing, and its behavioral consequence avoidance have been recognized to play indispensable roles in the development and maintenance of chronic pain. In fact, pain-related fear and avoidance behaviors can be more disabling than the pain itself (Crombez et al., 1999; Zale et al., 2013). Catastrophic beliefs and misinterpretations of pain can make people fearful of movements or activities that might trigger or worsen pain. This fear, collectively termed pain-related fear, can be acquired through both classical (Pavlovian) and operant learning, and can motivate pain behaviors such as activity avoidance (e.g., avoiding walks, avoiding heavy lifting) or 
safety-seeking behavior (e.g., using crutches or other aids, taking things slow). Both of these types of behavior may be adaptive at some point, especially if they effectively reduce the threat. However, in some situations -especially in relatively safe situations- they become maladaptive, and become associated with decreased functioning (Vlaeyen et al., 1995a) and may hinder treatment approaches (Volders et al., 2012). Paradoxically, these activity-limiting pain behaviors can even increase the threat value of the pain (Lovibond et al., 2009; van Vliet et al., 2018), and instigate a vicious cycle hallmarked by disuse and disability. This vicious cycle is the basis of the fear avoidance model of pain, describing a cascade of events triggered when a potentially harmful stimulus is considered highly threatening, when there is painrelated distress and when immediate pain control is given priority over other competing life goals (Fig. 2) (Vlaeyen et al., 2016). In line with the fear avoidance model, we posit that threat perception is key - that a potentially harmful stimulus or situation has to be perceived as highly threatening - and is a pivotal point where stress and its influences on threat processing come into play to further reinforce maladaptive threat learning.

\subsection{The acute stress response to threat}

Pain is emotionally salient and can trigger a stress response, contingent on the interpretation of a pain experience. The biological stress response is designed to encourage confrontation with or escape from the threat at hand, depending on the context, involving both the central and peripheral nervous systems across multiple time scales (Fig. 3). The fast, immediate response is driven by the autonomic sympathetic adrenal medullary (SAM) system which triggers the release of adrenaline and noradrenaline from the adrenal medulla, increasing heart rate, sweating, alertness, arousal, and focused attention. Typically, the SAM system normalizes within several minutes after stressor offset (Fig. 3B). The slower response, about 15-20 minutes later, is triggered by the hypothalamus activating the hypothalamic-pituitary-adrenal (HPA) axis, causing the release of glucocorticoids, including cortisol in humans (De Kloet et al., 2005; Joëls and Baram, 2009; Ulrich-Lai and
Herman, 2009). Cortisol can enter the brain and can bind to glucocorticoid and mineralocorticoid receptors (GR, MR, respectively), which are expressed abundantly in the limbic system and the PFC. These enable both rapid, non-genomic actions of cortisol as well as slow, gene-mediated (genomic) actions (delayed by about 60-90 minutes, and may last for several days to weeks, Fig. 3) (Joëls and Baram, 2009). Perhaps as important as the initiation of this cascade of events is the act of regulation, and shutting the system down once appropriate (i.e., once the stressor is removed, to restore homeostasis in the body). In addition, cortisol provides its own negative feedback to the HPA axis (via GRs), which is mediated at least in part by limbic and frontal structures such as the amygdala, hippocampus, and mPFC (De Kloet et al., 2005). Interestingly, these structures are among the key brain regions that are seemingly altered in chronic pain, both in terms of their structure (e.g., reduced hippocampal volumes; Mutso et al., 2012) and function (e.g., altered amygdala responses to emotional stimuli; Simons et al., 2016). Acute increases in cortisol secretion are adaptive for threat detection and consolidation of a threat memory (Maddox et al., 2019; Quaedflieg and Schwabe, 2018). Under acute stress, connectivity between the amygdala and other parts of the salience network (i.e., dorsolateral PFC and anterior cingulate cortex) is strengthened (Hermans et al., 2014, 2011; Quaedflieg et al., 2015), optimizing threat-processing through an attentional shift towards the threat. In the context of chronic pain this may be maladaptive, as it biases the perception of our experiences, including pain experiences, as threatening, and facilitates acquisition of the threat (pain) memory trace.

\section{When stress and pain collide}

\subsection{Stress effects on pain}

Effects of acute and chronic stress on acute pain. Stress is thought to be a physiological trigger that can activate the descending pain modulatory system (Terman et al., 1984), either facilitating (hyperalgesia) or inhibiting (hypoalgesia) pain signaling. Some studies show that acute stress increases heat pain thresholds in healthy volunteers (al'Absi and
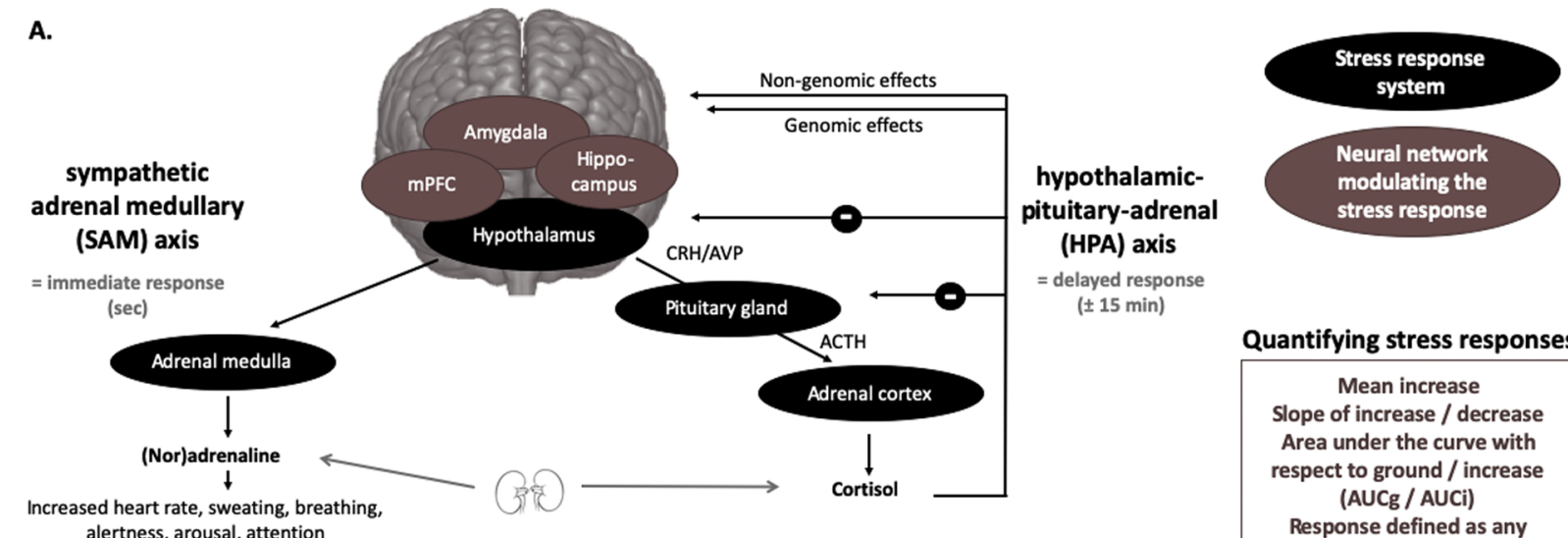

Quantifying stress responses

\begin{tabular}{|c|}
\hline Mean increase \\
Slope of increase / decrease \\
Area under the curve with \\
respect to ground / increase \\
(AUCg / AUCi) \\
Response defined as any \\
increase or increase $>1.5 \mathrm{nmol} / \mathrm{L}$
\end{tabular}

B. Different timings of the multiple stress systems
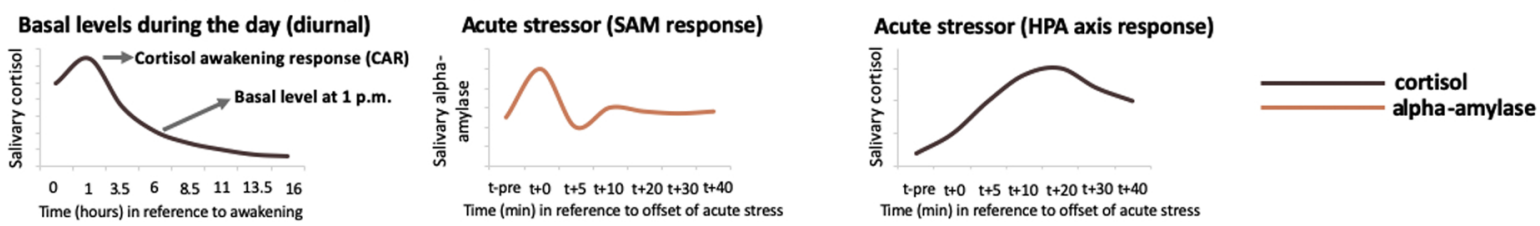

Fig. 3. The two major stress response systems and its modulation and timing. A. The sympathetic adrenal medullary (SAM) and the hypothalamic-pituitary-adrenal (HPA) axis stress responses are depicted, as well as the main brain areas modulating the stress responses. B. The different timings of the multiple stress systems, which need to be taken into account when assessing them. In addition, different ways of quantifying the stress response are depicted. ACTH $=$ adrenocorticotropic hormone, $\mathrm{AUCg} / \mathrm{i}=$ area under the curve with respect to ground/increase, $\mathrm{AVP}=$ Arginine-vasopressin, $\mathrm{CRH}=$ corticotropin-releasing hormone, $\mathrm{mPFC}=\mathrm{medial}$ prefrontal cortex. 
Petersen, 2003; Flor and Grusser, 1999; Timmers et al., 2018). This would allow one to focus attention to dealing with the situation at hand and focus on the pain and healing, which would be competing for attention, later. Interestingly, in one study this hypoalgesic effect was specific to participants showing a cortisol response to the stressor (Timmers et al., 2018), while in another study it was correlated with blood pressure (al'Absi and Petersen, 2003). These findings implicate the involvement of both the SAM and HPA axis stress response system. On the contrary, other reports show that acute stress can also result in hyperalgesia (Caceres and Burns, 1997; Crettaz et al., 2013; Rivat et al., 2007), which would allow the organism to attend to the experienced pain and protect itself to promote healing. A recent pharmacological study showed that increasing cortisol levels through administrating hydrocortisone resulted in hyperalgesia for visceral stimuli, but not for heat pain stimuli (Benson et al., 2019). The context or level of perceived threat may be crucial herein. Moreover, these contradictory findings are likely due to methodological differences like the stressor used - whether the experimentally-induced stressor is psychological or physiological in nature (or pharmacologically induced), the temporal distance between the stressor and the pain assessment, or whether or not there were competing goals (e.g., a reward) (Dickerson and Kemeny, 2004; Reinhardt et al., 2013; Ulrich-Lai and Herman, 2009). In addition, the effect of acute stress on pain experience is shown to be influenced by other factors, such as age, sex, and prior experiences to stressful and painful stimuli, psychosocial (cognitive, affective, and social) factors, but also by inflammatory processes (Chapman et al., 2008; Dickerson and Kemeny, 2004; Kudielka et al., 2009; Maier, 2003; Zankert et al., 2019). Indeed, acute stress was found to reduce pain modulation in men, and this effect was strongest in participants that showed the strongest stress response (in terms of perceived stress) (Geva et al., 2014). Furthermore, individuals with higher levels of fear of pain showed attenuated hypoalgesia following acute stress induction (Timmers et al., 2018), which is in line with findings regarding the debilitating effect of pain-related fears in the context of pain. Together, these findings suggest that the effect stress has on a pain experience may be linked to individual differences in the stress response as well as to individual differences in pain-related distress and threat perception.

The picture is similar for chronic stress: studies report hypoalgesia or analgesia (Clark et al., 1986), as well as hyperalgesia (Imbe et al., 2006). In patients with post-traumatic stress disorder (PTSD), a chronic stress syndrome, evidence of increased pain sensitivity has been found (Jenewein et al., 2016), although other studies report decreases in pain sensitivity. Defrin et al. (2015) have attempted to resolve some of these paradoxical findings. They found that patients with PTSD show increased pain thresholds to experimentally induced pain (i.e., decreased pain sensitivity), potentially due to reduced attention to stimuli (resulting from dissociation). Once experienced as painful though, patients showed more intense experience of pain, which might be caused by a bias towards threatening stimuli and increased anxiety (Defrin et al., 2015). This is well in line with the argument that there have to be heightened threat interpretations in order for stress to exert its debilitating influence.

Effects of acute and chronic stress on chronic pain - The small number of studies that have been conducted suggest that effects of acute stress on experimentally-delivered pain are similar or more pronounced in individuals with chronic pain. For instance, after an acute social stressor both healthy control participants and patients with fibromyalgia showed increased sensitivity to heat pain stimuli, while only patients with fibromyalgia showed increased sensitivity to pressure pain stimuli (Crettaz et al., 2013). Yet, this study failed to show a robust stress response in both groups (heart rate was only increased in patients, not in controls; no cortisol samples were taken), making it difficult to draw any firm conclusions. An enhanced hyperalgesic effect of acute stress on pressure pain sensitivity was also found in individuals with chronic headache compared to controls (Cathcart et al., 2008). This effect was correlated to perceived stress, but no other physiological stress measures were assessed. Other studies found no difference between individuals with chronic pain and controls in the effects of stress on the pain experience (e.g., Dufton et al., 2008; Vachon-Presseau et al., 2013a). Interestingly, this latter study found that individuals with a stronger total stress response displayed less neural activity in several pain-related brain regions (e.g., insula, nucleus accumbens, mid-cingulate cortex), independent of whether they were in chronic pain or not. This suggests that chronic pain status may not the most important factor, but individual differences in stress responses may be.

It is well documented that chronic pain and PTSD have a high comorbidity. Patients with PTSD often report chronic pain with estimations ranging from 20 to $80 \%$ (Asmundson et al., 2002). Also, the prevalence of PTSD symptoms has been found to be higher in individuals with chronic pain compared to individuals without chronic pain (Asmundson et al., 2002; Noel et al., 2016). It is difficult to determine how chronic stress and chronic pain specifically relate to each other, as studies are often cross-sectional and several risk factors and vulnerabilities are shared. For instance, anxiety sensitivity and avoidance behaviors have been implicated as an important mechanism underlying disability in both PTSD and chronic pain (Asmundson and Katz, 2009; Lopez-Martinez et al., 2014; Vinall et al., 2016). In addition to models of shared vulnerability, mutual maintenance models propose that there are multiple mechanisms at play through which PTSD and chronic pain might maintain each other (Sharp and Harvey, 2001; Vinall et al., 2016), including cognitive (e.g., attention bias), affective (e.g., negative affect) and behavioral (e.g., reduced activity levels) factors. For instance, in youth with chronic pain, the relation between PTSD symptoms and pain symptoms were found to mediated by the child's pain catastrophizing (Neville et al., 2018). Others even go as far as to suggest that chronic stress and chronic pain syndromes are two sides of the same coin (Abdallah and Geha, 2017), and highlight the central role of the limbic system and of learning mechanisms in both the maintenance of chronic stress and chronic pain.

\subsection{Stress dysfunction in chronic pain}

Dysregulation of the HPA axis has been reported in many chronic pain conditions. Several studies have investigated basal levels of cortisol in different chronic pain conditions, with conflicting results. Some studies found higher levels of basal cortisol in individuals with chronic pain compared to controls, others found lower levels of cortisol, and yet others found both (see also Woda et al., 2016). For instance, in a population-based study, patients with widespread pain and those 'at risk' for chronic pain (i.e., free of chronic pain, but with somatic complaints) were shown to have lower levels of basal cortisol (assessed in the evening and in early morning) (McBeth et al., 2005). Using six assessments of salivary cortisol during the day, however, Catley et al. (2000) reported higher average basal cortisol levels in patients with fibromyalgia and rheumatoid arthritis. The different sampling procedures may be crucial in explaining this difference. Another study using multiple samples during the day (awakening, $30 \mathrm{~min}$ after awakening, noon, afternoon and bedtime) also observed higher levels of cortisol in patients compared to controls (Vachon-Presseau et al., 2013b). In female patients with fibromyalgia, no differences in basal cortisol levels were found in comparison to a control group when samples were collected at multiple times during the day (McLean et al., 2005). However, patients also rated their momentary pain levels alongside the cortisol assessments and found that in the morning (after awakening, and $1 \mathrm{~h}$ after waking) there was a strong association between cortisol levels and momentary pain ratings that was not present during the rest of the day. Another study assessed cortisol levels over a longer period (i.e., several weeks to months) by taking hair cortisol samples instead of the standard momentary salivary cortisol assessment (Van Uum et al., 2008). Measures of hair cortisol represent daily summation of stress exposure, enabling one to normalize an individual's exposure to daily stress over a long period of time (e.g., $3 \mathrm{~cm}$ length segment of hair closest to scalp is 


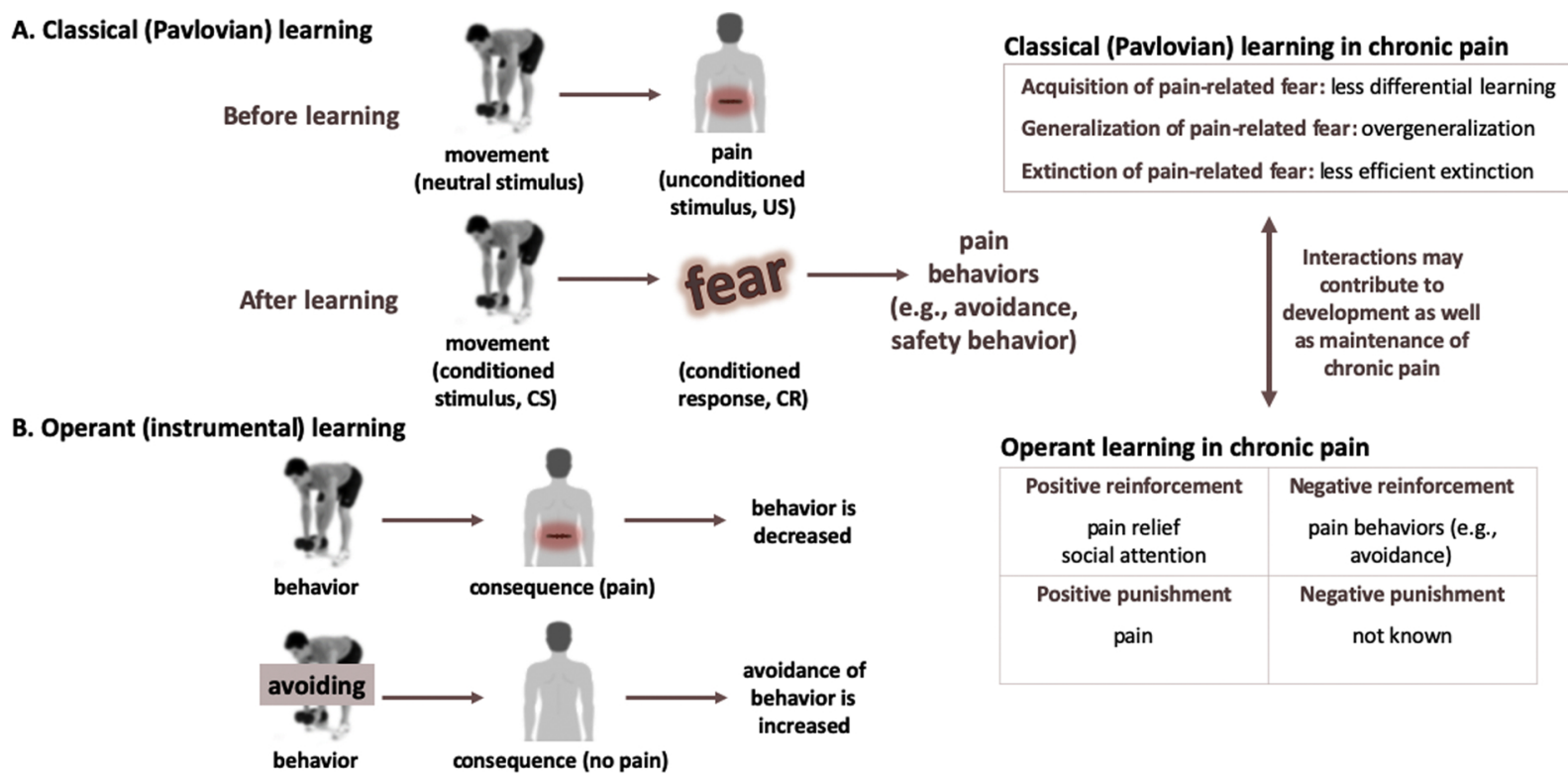

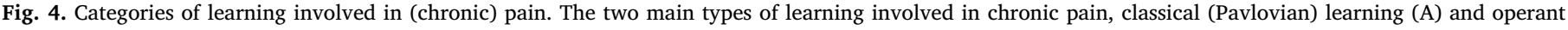

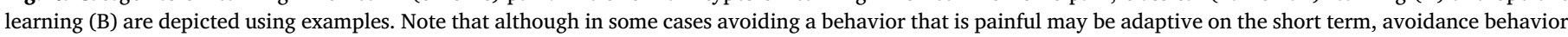

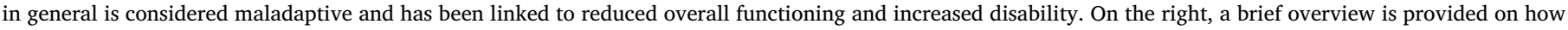
these types of learning are relevant for and/or altered in patients with chronic pain.

representative of cortisol incorporation into the hair over the most recent 3 months) (Slominski et al., 2015). The authors found elevated levels of perceived stress over the last four weeks (assessed using the Perceived Stress Scale) as well as elevated levels of hair cortisol in a group of patients with chronic pain, compared to controls, but no correlations between perceived stress symptoms and hair cortisol level (Van Uum et al., 2008). It is conceivable that the association between cortisol and chronic pain is dependent on the duration of the chronic pain condition. Heim et al. (2000) suggested that an initial hypercortisolism in chronic pain conditions is likely to perpetuate rapid exhaustion of cortisol levels in response to repeated short-term acute stressors, which is then followed by hypocortisolism. Specific studies that examine the importance of the duration of chronic pain, the effect of transitioning from subacute to chronic pain, and the effect of treatment are still lacking. Basal cortisol levels, however, are not particularly informative for whether the induced stress response to a threat is different in patients with chronic pain. As most studies find elevated levels of perceived stress as well, it could merely reflect elevated levels of stress instead of differential responses when facing acute stress.

In addition to basal levels, studies have focused on reactivity to assess both the responsiveness of the HPA axis and the ability to regulate its activity: non-induced cortisol awakening response (i.e., CAR; see Fig. 3B) and induced stress (i.e., acute stress induction). Cortisol levels fluctuate during the day. After waking there is a sharp increase in cortisol levels, followed by a steady decrease throughout the day. This CAR was observed in a large sample of 305 patients with chronic low back pain (Sveinsdottir et al., 2016). In comparison to a healthy control group, the CAR (from awakening to 30 min later) was significantly higher in patients, while the cortisol slope $(30 \mathrm{~min}$ after awakening to the evening) and basal cortisol levels at all single time points (awakening, 30 min after awakening, evening) were similar across groups. In addition, they found that CAR was negatively associated with several self-reported outcomes (e.g., subjective health complaints, and pain intensity). Although the CAR is also considered to reflect HPA axis responsiveness, it does not reflect a response to an actual threat. One fMRI study with patients with chronic pain and controls exposed participants to painful thermal stimulations in the scanner and assessed cortisol reactivity to the painful heat stimulus - the acute stressor (VachonPresseau et al., 2013a). The study found no difference in cortisol reactivity between groups, suggesting normal cortisol reactivity to threat stimuli. Other studies aimed to examine stress reactivity in patients with chronic pain, but failed to induce significant stress responses (Meeus et al., 2015; Muhtz et al., 2013), hindering the investigation of such responses. Indeed, not all stressors elicit an HPA axis stress response in all individuals. A stress response could be defined as any increase in cortisol greater than zero, while others argue that only increases in cortisol of $1.5 \mathrm{nmol} / \mathrm{L}$ or higher (Miller et al., 2013) or even $2.5 \mathrm{nmol} / \mathrm{L}$ or higher (Van Cauter and Refetoff, 1985) are indicative a cortisol secretion. Even in well-controlled laboratory settings, not all participants show evidence of such 'real' cortisol responses. One study comparing different well-known acute stress paradigms observed an increase of $2.5 \mathrm{nmol} / \mathrm{L}$ or higher in $40 \%-95 \%$ of (healthy) participants, dependent on the paradigm (Smeets et al., 2012). A meta-analysis has suggested that stressors that are uncontrollable and have a social-evaluative threat element are most likely to activate the HPA axis (Dickerson and Kemeny, 2004). Not many studies, however, report data on cortisol responses on an individual level, making it difficult to judge whether stress inductions were truly activating the HPA axis stress system. And, this also makes it challenging to compare groups and conditions, as well as to provide mechanistic links between stress response (dys)regulation and (chronic) pain (see also Zankert et al., 2019).

\section{The relevance of learning mechanisms in pain and the role of stress}

\subsection{Relevance of threat learning in chronic pain}

Learning plays a central role in chronic pain. Now, we will delve further into the relevance of threat learning in chronic pain. Pain-related fear can be acquired via associative learning, such as classical or Pavlovian conditioning in which people learn that certain movements or activities are potentially paired with a pain experience (Fig. 4A). Through classical conditioning, previously neutral movements/activities become conditioned stimuli (CS), able to elicit conditioned responses (CR) (e.g., pain-related fears, worries) without the presence of pain. As pain is considered an emotionally-salient stressor and can be seen as threat, this can also be referred to as threat learning or threat- 
safety learning. This threat learning can occur in multiple ways, including through direct experience, by observing others (e.g., via facial expressions), and by instruction (den Hollander et al., 2010). Experimental studies in healthy participants have shown that pain-related fear, acquired through classical conditioning (see e.g., Biggs et al., 2017; Meulders and Vlaeyen, 2013), interferes with perceptual discrimination (Zaman et al., 2015), can amplify pain (i.e., causes hyperalgesia; Madden et al., 2015), promotes sensitization (Jensen et al., 2015), and increases generalization of the conditioned stimulus (where similar stimuli can also induce fear responses; Meulders and Vlaeyen, 2013). In certain contexts, these consequences may be adaptive. However, in the context of chronic primary pain, this learning and generalizing may become excessive, no longer related to an imminent threat, and maladaptive as it may contribute to increased safety and avoidance behavior and in turn decreased functioning. Classical conditioning studies have also shown that conditioned pain-related fear can be reduced using extinction, where the conditioned stimulus or context is repeatedly presented in absence of the aversive stimulus and hence loses its predictive value (see e.g., Biggs et al., 2017; Meulders and Vlaeyen, 2012). The clinical analogue of extinction, Exposure in Vivo (EXP), has been shown to successfully reduce pain-related cognitions, fears and functional disability in patients with chronic pain (de Jong et al., 2005; Leeuw et al., 2008), and there is evidence that it can also reduce pain intensity in some individuals (den Hollander et al., 2016). Extinction is generally thought to reflect the formation of a new safety memory, rather than eradication of the previously-learned threat memory (Moustafa et al., 2013; Phelps et al., 2004). Similar to other types of learning, extinction learning also occurs in different phases including acquisition, consolidation and retrieval of the extinction memory trace (Quirk and Mueller, 2008). When extinction learning has been successful, re-presenting the original threat cue (CS) should result in retrieval of the extinction memory. Yet, extinction retrieval is not always successful. Poor extinction retrieval may occur following spontaneous recovery of fear, after renewal (i.e., recovery of fear to a cue when encountered again in the initial context or in a novel context), or after reinstatement (i.e., recovery of fear to a cue after re-presenting the unconditioned stimulus). Some work has focused on making the fear memory trace unstable by re-presenting the threat cue (CS; after acquisition, termed reactivation), after which reconsolidation of the fear memory trace would occur (Nader and Hardt, 2009). Interestingly, during this phase, the fear memory trace would be more susceptible to extinction (Schiller et al., 2013).

In addition to classical (Pavlovian) learning, research has shown the importance of operant learning in chronic pain (Fordyce et al., 1968). Operant learning is a type of associative learning too, and is based on the premise that certain behaviors are (implicitly) associated with meaningful consequences (Fig. 4B). Consequences that further strengthen behavior are termed 'reinforcers' and are proposed to either increase or decrease behaviors. For example, pain behavior displayed by an individual can be positively reinforced with for example social attention (e.g., a parent soothing their child in pain), as well as negatively reinforced (e.g., behavior to avoid experiencing pain; such as not lifting weights anymore). Through this type of learning, conditioned responses (e.g., pain-related fear, worries) may lead to avoidance and/ or safety behaviors (den Hollander et al., 2010; Vlaeyen et al., 1995b). Thus, it is relevant to note that it is a dynamic interaction between Pavlovian learning mechanisms through which pain-related fear is acquired and generalized, and operant learning mechanisms through which the resulting pain behaviors are reinforced and maintained over time, which may preserve threat value of movements/activities and threat beliefs - thereby contributing to the development as well as the maintenance of chronic pain. An important consideration here is that pain is not only a punishment, but the relief from pain is a powerful reward (Navratilova and Porreca, 2014; Nees and Becker, 2018). Another route in which operant learning can be involved in maintenance of chronic pain is via deficient positive reinforcement of healthy or "well" behavior (e.g., working or social involvement). In sum, painrelated fears are acquired through associative -both classical (Pavlovian) and operant- learning mechanisms, and there is evidence that threat-safety learning is impaired in patients with chronic pain (see section 4.4).

\subsection{How stress affects learning mechanisms and the relevance for pain}

Not surprisingly, there are strong connections between brain networks that regulate the stress response (mainly in limbic areas) and regions that are involved in learning and memory (Ulrich-Lai and Herman, 2009). Our stress system is more easily triggered by situations that we learn are threatening and less easily triggered by situations identified as harmless. The effects of stress on learning and memory are complex, dynamic, and dependent on timing (e.g., whether stress and learning occur simultaneously or consecutively) and context (e.g., whether the to be learned information is stressor-related) (de Quervain et al., 2017; Diamond et al., 2007; Joels et al., 2006; Quaedflieg and Schwabe, 2018; Quaedflieg et al., 2013). The rapid, non-genomic effects of cortisol result in a memory formation mode facilitating encoding and early consolidation of threat-related information (Joels et al., 2008). When pain is considered a high threat, it has the capacity to trigger facilitation of encoding and consolidation of the fear memory. The delayed, genomic effects of cortisol induce a memory storage mode in which consolidation of the threat memory is protected from interference by suppressing the encoding of any stressor-unrelated information (Joels et al., 2011; Schwabe et al., 2012).

Acute stress also influences how memory guides our behavior: stress has been found to impair values-based goal-directed instrumental behaviour (Dias-Ferreira et al., 2009; Schwabe and Wolf, 2010, 2011; Smeets et al., 2019) by impairing the outcome-based prefrontal cortex system (Quaedflieg et al., 2019; Quaedflieg and Schwabe, 2018). Work has indeed shown that acute stress triggers a shift in neural networks (Hermans et al., 2014, 2011; Quaedflieg et al., 2015): it reallocates resources to the salience network (i.e., including amygdala, anterior cingulate cortex, anterior insula), which is meant to reorient attention and direct efforts to potential threats, thereby facilitating vigilance and threat processing. This shift is at the expense of the executive control network (i.e., including dorsolateral/-medial PFC, posterior parietal cortices), which is devoted to higher order cognitive tasks, promoting goal-directed behaviour. The shift from values-based goal-directed (or outcome-based) to rule-governed, stimulus-controlled behaviour seems especially relevant when it comes to linking stress with pain-related threat learning. Immediate pain control and avoidance behavior would be considered as stimulus-controlled (habit-like, inflexible, rule-governed) behavior, while prioritizing life goals (i.e., activity engagement, approach behavior; see Fig. 2) would be considered values-based goaldirected (flexible) behavior. Importantly, the amygdala, the core threat center in the brain, has an important role in this shift (de Quervain et al., 2017; Quaedflieg et al., 2013). In chronic pain, amygdala functioning has also been found to be abnormal (Hashmi et al., 2013; Neugebauer et al., 2004; Simons et al., 2016) and changes in amygdala functioning and connectivity have been associated with treatment success (Simons et al., 2014b). Moreover, both structural and functional alterations have been observed in patients with chronic pain in key nodes of both the salience network (e.g., anterior insula, anterior cingulate cortex) (Borsook et al., 2013; Cauda et al., 2014; Kucyi and Davis, 2015) as well as the executive control network (e.g., dorsolateral/-medial PFC) (see e.g., Jiang et al., 2016; Lorenz et al., 2003; Seminowicz and Moayedi, 2017). Thus, impaired goal-directed behaviour resulting from stress provides another key point where stress exerts its influence on chronic pain when seen through the lens of the fear avoidance model.

In addition to affecting which memory system drives our behavior, acute stress is thought to affect the specificity and flexibility of memory. Acute stress and cortisol create a shift from detailed episodic encoding 
(driven by the hippocampus) to more abstract, gist-based memory formation, thought to be due to attentional narrowing (Kensinger, 2004; Schwabe, 2017). Furthermore, acute stress is thought to generally reduce the incorporation of contextual cues into memory traces, and to reduce memory flexibility (Dandolo and Schwabe, 2016; Kluen et al., 2017a). More abstract, gist-based memory traces with less contextual cues and less flexibility may facilitate threat generalization through imprecise encoding. Generalizing the fear memory towards similar threatening situations may be adaptive, but overgeneralization to potentially safe situations is not. Interestingly, imprecise encoding and overgeneralization of threat have been hypothesized to be key elements driving maladaptive behavior in patients with chronic pain (Moseley and Vlaeyen, 2015). Evidence further suggests that acute stress, as well as cortisol administration, impairs the integration of new information into stored memory traces (Kluen et al., 2017b), thus interfering with the updating of memory traces, which may have important negative consequences for extinction learning.

Taken together, acute stress affects memory in three ways: 1) it facilitates encoding and consolidation (i.e., acquisition) of the threat memory, 2) it compromises values-based flexible behavior and shifts our behavior to more rule-governed inflexible behavior, and 3) it reduces the specificity and flexibility of memory, facilitating overgeneralization of the threat memory trace.

\subsection{Effects of stress on threat learning specifically - what do we know so} far?

The effects of stress on learning of emotionally-salient material have been studied extensively. The effects of stress on threat learning (also often referred to as fear conditioning) specifically have received less attention. Evidence from animal studies suggests that stress facilitates the acquisition and consolidation of cued fear (Raio and Phelps, 2015). In humans, there are only a few studies addressing effects of stress on threat learning. In one study, an acute stress induction $25 \mathrm{~min}$ before threat learning impaired neural correlates of fear acquisition in men, while having facilitating effects in women (Merz et al., 2013). Interestingly, cortisol administration was found to reduce pain-related fear in the context of visceral stimuli (in healthy participants), while it did not affect heat pain stimuli, and had no effects on contingency awareness (Benson et al., 2019). Fear generalization was affected by acute stress as well, but only when participants were stressed after a delay ( $24 \mathrm{~h}$ after threat learning) and not when stressed immediately following threat learning, suggesting that older threat memories are more susceptible to stress-induced overgeneralization (Dunsmoor et al., 2017). In another study, it was found that individuals who were recently exposed to trauma also showed overgeneralization, compared to those who were not recently exposure to trauma (Harnett et al., 2018). With respect to extinction learning, it has been suggested that cortisol may facilitate extinction learning by impairing memory retrieval of threat-related memories and at the same time enhancing the consolidation of new memories (de Quervain et al., 2009). In line with this, animal studies have found that administration of glucocorticoids after retrieval enhanced the consolidation of extinction memory (Abrari et al., 2008; Cai et al., 2006) while blocking synthesis of glucocorticoids reduced extinction learning (Blundell et al., 2011). In humans, inducing acute stress directly before memory retrieval and extinction resulted in a reduction in retrieval but no differences in extinction of the threat memory (Bentz et al., 2013). Other studies have found that inducing acute stress preceding extinction learning had an impairing effect, thus showing reduced extinction learning and thus greater threat memory recovery (Raio et al., 2014). Moreover, acute stress impaired the retrieval of the original threat memory trace (Merz et al., 2014). Yet, in neutral (non-emotional) learning paradigms, the opposite findings have been reported (i.e., inducing acute stress impaired extinction learning; Hamacher-Dang et al., 2013). Taken together, these studies illustrate the crucial role of timing (e.g., whether stress is experienced at the same time as extinction, or beforehand) and suggest the effect of cortisol on extinction learning is phase-dependent (Elsenbruch and Wolf, 2015). When stress is experienced around the same time as extinction, the stressor shifts the dominance from the mPFC (involved in extinction learning, normally inhibiting amygdala to reduce threat value) to the amygdala (increasing threat value and facilitating the shift to rulegoverned stimulus-controlled behavior), resulting in impaired extinction learning (Akirav and Maroun, 2007). Another important factor is the controllability of the stressor. One study exposed participants to different types of stressors, who then completed a threat learning procedure one week later (Hartley et al., 2014). Participants who were exposed to a controllable (escapable) stressor showed improved extinction learning and no spontaneous recovery of fear, while participants who were exposed to an uncontrollable (unescapable) stressor showed impaired fear extinction learning and increased responses to fear. Other studies have shown that controllability, however, only diminished neural activity to the threat in relevant brain regions (medial prefrontal cortex, hippocampus) when it was predictable as well (Wood et al., 2015).

Studies in clinical populations suggest that stress facilitates the recovery (return) of fear (Jacobs and Nadel, 1985), but this is likely depending on whether the stressor is acute or prolonged, as chronic stress in rats has been found to impair extinction retrieval (Miracle et al., 2006; Wilber et al., 2011). Several studies performed in the context of exposure treatment show favorable effects of cortisol on extinction learning. For instance, oral administration of cortisol prior to extinction-based (exposure) treatment for phobia enhanced fear reduction (de Quervain et al., 2011; Soravia et al., 2014). Morning sessions of exposure treatment in phobia patients were found to be more effective compared to evening sessions, potentially due to higher basal levels of morning cortisol (Lass-Hennemann and Michael, 2014). Another study also linked the CAR to exposure treatment success in phobia patients by showing that higher absolute cortisol levels as well as higher CAR on exposure days predicted reduced threat appraisal and improvements in perceived control (Meuret et al., 2015). Post-exposure cortisol administration, however, had opposite effects, as it did not improve outcome in patients with a spider phobia, and even resulted in stronger fear renewal at follow-up (Raeder et al., 2019).

Another line of research shows that cortisol enhances the reconsolidation of fear (Drexler et al., 2015), although findings are not consistent (Bos et al., 2014; Schwabe and Wolf, 2010). In humans, enhancing effects of cortisol on reconsolidation after reactivation have been found to be sex-dependent, as it was only demonstrated in men (Meir Drexler and Wolf, 2017). In any case, for patients with chronic pain, this poses both challenges as well as opportunities. Whenever patients experience exposure to their conditioned stimuli (e.g., feared movements) and hence their memory trace is reactivated, the subsequent reconsolidation might be strengthened under stressful conditions (Elsenbruch and Wolf, 2015). On the other hand, the unstable memory trace also provides opportunities for intervention. It has been suggested that influencing the reconsolidation of threat memories is highly advantageous as the original memory trace is affected, while pure extinction would leave the original trace (in amygdala) intact and would rather regulate its expression by PFC-inhibition of the amygdala. An experimental study indeed showed that extinction during reconsolidation resulted in a more persistent reduction of conditioned responses and in diminished involvement of the PFC (Schiller et al., 2013). A recent meta-analysis of animal work furthermore showed that exercise (i.e., potentially reactivating threat memory traces) modulated extinction learning, which was especially true for operant extinction paradigms (Roquet and Monfils, 2018). It would be interesting to examine these concepts in Exposure In Vivo (EXP) treatment for chronic pain, which is the clinical analogue of extinction learning. It might be the case that the CSs will be reactivated but under conditions of reduced or no stress, hampering or preventing reconsolidation. Unfortunately, few studies have explicitly examined effects of acute stress on 
acquisition, generalization, or extinction of pain-related fear (see Elsenbruch and Wolf, 2015, for a further discussion).

Thus, cortisol seems to facilitate the acquisition and consolidation of threat memory traces, but this may be different across men and women. It also facilitates overgeneralization, but only when stress occurs after learning. And cortisol seems to facilitate extinction, but it has also been shown to enhance reconsolidation of fear which would hamper extinction learning. It is yet unclear how these differences arise, and whether the perceived threat value may be important here. Also, only a few of these studies have been performed in the context of pain and chronic pain, which begs the question whether findings would be similar when examined in the context of pain.

\subsection{Impairments in threat learning in chronic pain}

Based on the premise that 1) stress affects threat learning, 2) threat learning is of major importance in chronic pain, and 3) patients with chronic pain have stress dysfunctions, one would expect altered threat learning in patients with chronic pain. Indeed, alterations in pain-related fear acquisition have been identified in patients, including in patients with fibromyalgia (Meulders et al., 2015), subacute back pain (Nees et al., 2019), chronic low back pain (Klinger et al., 2010; Schneider et al., 2004), irritable bowel syndrome (Icenhour et al., 2015), hand pain (Meulders et al., 2014), and headache (Klinger et al., 2010). Fig. 3 gives an overview of findings in patients with chronic pain. In a recent meta-analysis, patients with chronic pain are overall found to show reduced differential learning, although evidence is still inconsistent and weak (Harvie et al., 2017). Patients are less able to distinguish between threat signals and safety signals than controls, and hence show an increased fear response to signals that cue safety. Their ability to predict potential harm is therefore impaired and may contribute to the maintenance of pain-related fear and pain behaviors (e.g., avoidance). Moreover, studies have found that while both patients and controls generalized their fear to stimuli that were similar to the painful movements (similar to the threat cue; conceptualized as adaptive), patients also generalized their fear to movements that were similar to the non-painful movements (i.e., similar to the safety cue; non-differentiated generalization, considered maladaptive; Meulders et al., 2014, 2015). These findings may be in line with reduced tactile acuity, as found in patients with chronic pain (Catley et al., 2014), which would hinder tactile discrimination of similar, but distinct stimuli. The overgeneralization of conditioned responses was confirmed by the metaanalysis of Harvie et al. (2017) and supports the hypothesis that imprecise encoding is a hallmark of chronic pain that leads to overgeneralization (Moseley and Vlaeyen, 2015), Furthermore, Meulders and colleagues showed that although pain-related fear and pain expectancy ratings to generalized stimuli was reduced after extinction in both controls and patients, responses remained higher in the patients with fibromyalgia, despite corrective feedback (Meulders et al., 2017). The authors suggest that this behavior is indicative of excessive protective responses as the experiment shows that pain-related fear (i.e., a protective response) spreads more easily in patients with fibromyalgia and is more resistant to change. Other studies have also demonstrated less efficient extinction learning in individuals with chronic pain (e.g., Labus et al., 2013; Schneider et al., 2004). Moreover, extinction of painrelated fear is hampered by safety and avoidance behavior (Volders et al., 2012), presenting a challenge for exposure-based treatments. Interestingly, only in youth with chronic pain presenting with high pain-related distress (i.e., maladaptive pain cognitions and fears) altered neural correlates of extinction learning were observed (Heathcote et al., under review), further illustrating the importance of pain-related distress, overshadowing the importance of chronic pain status.

Alterations in operant learning have been also been identified in individuals with chronic pain. There is evidence that patients may be more sensitive to reinforcers compared to pain-free controls. For instance, they show more difficulties extinguishing reinforced behaviors
(Flor et al., 2002). Moreover, evidence suggests that, in chronic pain, reward processing is impaired (Borsook et al., 2016; Navratilova et al., 2016). For instance, responsiveness to rewards (i.e., emotional responses to presence or anticipation of a reward), but not reward drive (i.e., tendency to pursue rewards), was reduced in patients with chronic pain in comparison to controls (Elvemo et al., 2015). Impairments in operant learning have further been found to interfere with normal habituation and sensitization processes in patients with fibromyalgia (Becker et al., 2011).

Taken together, there is growing evidence that chronic pain is characterized by maladaptive threat learning, with both classical (cued and contextual) and operant learning factors at play. More specifically, patients with chronic pain show reduced ability to learn to differentiate threat and safety signals, impaired extinction of threat-related information, overgeneralization of conditioned responses, and deficient reward learning. This is well in line with the effects of stress on learning as described above, including facilitated acquisition of the threat memory as well as increased (over)generalization.

\section{How it all comes together in threat-safety learning}

\subsection{Theoretical integration of stress, (chronic) pain, and threat learning}

We have described the importance of threat learning in the development and maintenance of chronic pain, as well as the effect of stress on these learning and memory processes, and how stress response systems are dysregulated in patients with chronic pain. In an attempt to integrate these different lines of evidence and generate specific and testable hypotheses, we argue that interactions between stress, pain and threat learning operate on four main levels which are outlined in Fig. 2 and further discussed below.

First, we posit that one key interaction between pain, threat and stress is that pain-related distress and high threat value facilitate activation of the HPA axis stress response. Indeed, not all stressors are able to elicit an HPA axis stress response, and many studies have struggled with inducing significant cortisol responses. A meta-analysis has suggested that stressors need to be uncontrollable and have a social-evaluative threat element in order to elicit a cortisol response (Dickerson and Kemeny, 2004). Following this, we would expect individuals with high pain-related distress (e.g., fear of pain, catastrophizing) to be more likely to show an HPA axis response to an acute stress induction compared to individuals with low pain-related distress. There is some evidence to support the claim that pain-related distress is a mediating factor, as fear of pain was related to the magnitude of a stress-induced hypoalgesic effect in healthy participants (Timmers et al., 2018). Also, individual traits such as anxiety sensitivity have been suggested to be related to individual stress responses (Bae et al., 2019; Weger and Sandi, 2018). Related, if pain-related distress is more relevant than chronic pain status itself, one would furthermore expect differences between patients with chronic pain who present with high versus low pain-related distress. In addition, we would expect that manipulating the perceived threat level of a stimulus would increase the likelihood of activating the HPA axis system. In turn, an HPA axis stress response in the context of emotional distress and threat may amplify a nociceptive stimulus, making it more likely that a nociceptive stimulus is perceived as painful or making the stimulus more painful.

Second and third, acute stress increases alertness, arousal, and attention to threat and optimizes threat-processing through interactions with the amygdala and other regions in the salience network, and it compromises adaptive goal-directed behavior and cognitive flexibility and control via effects on the PFC. We posit that a stress response biases our system towards perceiving a potentially harmful stimulus or situation as a high threat and in turn to prioritize immediate pain control. Following this position, we would expect that an acute stress induction (e.g., using the Trier Social Stress Test or the Maastricht Acute Stress Test; Kirschbaum et al., 1993; Smeets et al., 2012) would increase the 
perceived threat of a potentially painful stimulus, and that the magnitude of the stress response would be related to threat levels. Also, increased stress responses would be expected to result in increased painrelated stimulus-controlled behavior (e.g., avoidance behavior). Experimental tasks that assess goal- versus stimulus-controlled behavior or that allow assessment of avoidance behavior (e.g., using a forcecontrolled robotic arm; Meulders et al., 2016) would be needed in combination with acute stress inductions to examine this further. As an alternative to acute stress inductions, one could relate stress measures (e.g., blood pressure or alpha amylase for the SAM stress response, cortisol for the HPA axis stress response; see Fig. 3 or Strahler et al., 2017) to threat appraisals.

Fourth, when pain is perceived as a high threat and immediate pain control is prioritized, stress may further affect threat learning. Acute stress biases memory formation towards threat-related information and thus impairs encoding and retrieval of threat-unrelated information. It furthermore interferes with updating of memory traces, potentially hampering extinction learning. In addition, acute stress may facilitate reconsolidation of the threat memory trace after reactivation by reexposure to the threatening movements and activities, further strengthening and maintaining the threat memory trace as well as hampering extinction. Also, acute stress and in particular cortisol shifts memory formation from detailed episodic to more abstract, gist-based traces, with less contextual cues and less flexibility, which may facilitate generalization of pain-related fear through imprecise encoding. Thus, taken together, stress may facilitate acquisition, generalization and reconsolidation of the threat memory, while also modulating extinction learning. Following this, we would expect that threat learning parameters, such as self-reported fear, worries or expectancy ratings following fear acquisition would be related to stress measures. In addition, we would expect that that stress affects flexibility of the threat memory, which would in turn be associated with the level of (over) generalization. Studies are emerging that tap into stress effects on painrelated threat learning. We would recommend taking into account variables such as pain-related distress (or more broader traits, such as anxiety sensitivity) as well as perceived threat value of stimuli. It appears that stress may facilitate extinction learning by facilitating the consolidation of the extinction memory (i.e., facilitating extinction learning), while other evidence suggests that reconsolidation of the original threat memory may be facilitated by stress during extinction learning (i.e., hampering extinction learning). As we have suggested before, the threat value may again be a crucial factor. Reducing threat value by for instance employing pain science education may be beneficial in this context (Moseley and Butler, 2015).

While we describe intersections between pain, stress and threat that can generate specific, testable hypotheses, most of the evidence has been derived from healthy participants with healthy stress response systems. Evidence is replete on the effects of chronic stress, and how a dysregulated HPA axis would modulate effects and interactions outlined here. Research has demonstrated that chronic stress induces changes in key regions involved in HPA axis regulation; these regions are important for learning and memory. For instance, chronic stress induces atrophy in hippocampus and mPFC (Herman et al., 1995; Magarinos and McEwen, 1995; Radley et al., 2008), compromising their involvement in memory and reward processes. As the amygdala is also key to instigating an HPA axis response and regulating HPA axis negative feedback, chronic stress effects on the amygdala would further reinforce any HPA axis mediated effects on chronic pain and threat learning. In patients with chronic pain, there appears to be evidence of both increased as well as decreased basal cortisol levels and CAR responses, with little to no evidence of impaired stress reactivity. Research needs to be done to examine whether stress reactivity is indeed unaffected in patients with chronic pain, and whether this may also be dependent on their level of pain-related distress. Also, it should be investigated if and how the duration of chronic pain affects the stress response systems. It has been suggested that initially, patients with chronic pain experience repeated short-term acute stressors (which is in line with our hypothesis that pain, if experienced as a high threat, facilitates eliciting stress responses) and hence experience rapid exhaustion of cortisol levels (Heim et al., 2000). This would then be followed by hypocortisolism, which may impair activation of the HPA axis when necessary. Supporting evidence for this idea comes from a study comparing individuals with subacute versus chronic back pain (Nees et al., 2019), showing that patients with subacute pain showed increased feedback sensitivity of the HPA axis (i.e., in response to a dexamethasone suppression test, to investigate the HPA axis regulation), while patients with chronic back pain and healthy controls did not. This was further correlated with pain intensity, and mediated by anxiety, further supporting the relevance of psychological mechanisms. In order to tease out different HPA axis alterations, thorough assessment of basal cortisol levels as well as cortisol reactivity is important. Additionally, pharmacological studies may give more insights into how for instance fear acquisition is modulated by increases in cortisol, and how the HPA axis is modulated during recovery. Neuroimaging studies would be very helpful here as well, as they can pinpoint what brain areas are modulated by stress. To get a better understanding of the temporal or causal relations between stress allostatic load and chronic pain, it would be of value to integrate stress assessments (i.e., CAR or cortisol reactivity to acute stress induction) into studies focusing on transitioning from acute to chronic pain or on treatment of chronic pain. On the flipside, one could examine changes in pain sensitivity and pain-related distress following stress reduction treatments. Several studies have already shown the potential of stress management programs in patients with chronic pain (Jeitler et al., 2015; Metikaridis et al., 2016)

\subsection{Methodological considerations and future directions}

Further integration of research in the fields of stress and chronic pain is necessary. Careful consideration of variation in basal cortisol levels and cortisol reactivity across individuals is needed. For instance, sex has an influence on cortisol levels during the day (Miller et al., 2016), on cortisol reactivity to acute stress paradigms (i.e., induced response) (Kudielka et al., 2009), as well as on the effects of acute stress on threat learning (e.g., Merz et al., 2013). These sex differences may not be mutually exclusive. It is plausible that sex differences in cortisol reactivity may result in differing learning potentials between males and females. Indeed, women with low estrogen levels (a major sex hormone) have shown differential brain responses and more subjective distress to an acute psychosocial stressor compared to women with high estrogen levels (Albert et al., 2015), as well as increased return of fear during extinction recall compared to women with high estrogen levels (irrespective of whether they had an anxiety disorder or not; Li and Graham, 2016). Furthermore, estrogen levels have been linked to deficits in extinction learning in women with PTSD (Glover et al., 2012). For females, the stage of menstrual cycle has also been found to influence cortisol levels, and hormonal contraceptives typically blunt cortisol reactivity (Miller et al., 2016). Hormonal contraceptives have also been found to enhance fear learning when combined with cortisol (while fear learning was reduced in free-cycling women; Merz et al., 2012) impair extinction recall, an effect that is likely due to their inhibition of estrogens, as administering estradiol (estrogen agonist) reversed this effect and even facilitated extinction recall (Graham and Milad, 2013). In addition to sex, other factors contribute to individual differences in cortisol reactivity, including genetic, psychological (e.g., resilience), and social (e.g., social support) factors, as well as early life experiences and personality traits (Kudielka et al., 2009; Zankert et al., 2019). Consideration of potential sources of variation in studies examining cortisol is therefore warranted. Measuring relevant constructs where possible and ensuring group differences are not confounded by these and other factors is highly advised. Note that few studies have focused on comparing different types of chronic pain in this context. In this review, we have considered broad evidence across different 
populations of chronic pain, as well as different age groups. We believe that this is important given that we propose that the interactions between stress, pain, and threat learning is a transdiagnostic mechanism relevant for all types of chronic pain.

As outlined in this review, the stress response system is highly complex and its effects on the body and brain are highly dynamic. Here, we have focused mainly on the HPA axis stress response and its major stress hormone cortisol. However, research has shown that the SAM stress response also influences learning and memory, including threat learning (Giustino and Maren, 2018), and that the SAM and HPA axis stress responses interact (Quaedflieg and Schwabe, 2018). Assessing physiological markers of SAM (blood pressure and alpha-amylase) in addition to levels of an HPA axis marker such as cortisol within the same study would give a more complete assessment of physiological stress. The effects of acute and chronic stress on the immune system are well established too, with a wealth of data showing that stress dysregulates inflammatory responses with profound effects on health (Dhabhar, 2014; Segerstrom and Miller, 2004). For instance, in patients with PTSD there is converging evidence of immune system dysfunction, and there is high co-morbidity with autoimmune and inflammatory diseases (Neigh and Ali, 2016; Pace and Heim, 2011), which may explain the high comorbidity between PTSD and chronic pain as well. Moreover, several inflammatory markers have been found to affect pain sensitivity (see e.g., Cruz-Almeida et al., 2012; Ren and Dubner, 2010) and to be up- or down-regulated in patients with chronic pain (Totsch and Sorge, 2017; Uceyler et al., 2006). Hence, the effects of stress on the immune system are relevant in the interaction with pain and conditions of chronic pain as well. A thorough consideration of how this may be due to interactions with stress is, however, beyond the scope of the current review (but see e.g., Maier, 2003). What is clear, however, is that efforts should be taken to assess different facets of the complex stress response and its effects on bodily systems in an effort to separate effects. While cortisol is one important factor, it will be important to continue to examine how cortisol effects differ from those effects induced by the more complex experience of stress as a whole.

Here, we did not review developmental aspects. We would be remiss, however, to not mention the existing body of literature on the effects of early life stress and adverse childhood experiences (ACEs) on the risk of developing disorders related to stress, pain and other health outcomes (Jones et al., 2009; McLaughlin et al., 2017; Nelson et al., 2017; Oh et al., 2018). ACEs have also been investigated in the context of HPA axis functioning specifically. In fact, the HPA axis only becomes mature and shows its diurnal rhythm by the age of 4 years (Jessop and Turner-Cobb, 2008), underscoring the enduring impact that exposure to early life stress and ACEs can have on the developing brain. For instance, maternal cortisol levels have been found to impact brain development in such a way as to increase the child's vulnerability for affective or pain disorders later in life (Buss et al., 2012; Duthie and Reynolds, 2013). Also, it has been shown that children exposed to early life stress or adverse childhood experiences have reduced prefrontal cortex volumes as well as dysregulated HPA axis (as assessed using hair cortisol) and elevated immunological levels in comparison to healthy controls (Danese and McEwen, 2012; Palmer et al., 2013). Furthermore, early life stress has been found to be associated with altered receptor sensitivities within the HPA axis and blunted reactivity (Carpenter et al., 2007), and with reduced hippocampal-prefrontal connections that might impact learning (Sripada et al., 2014).

A final consideration is the effect of pharmacological pain treatment. Pain medication is heavily prescribed in patients with chronic pain, and the most effective medications work via the opioid (e.g., fentanyl, codeine, morphine) or anti-inflammation (i.e., nonsteroidal anti-inflammatory drugs [NSAIDs] such as acetylsalicylic acid or ibuprofen) systems, while low dose anti-depressants, anti-anxiolytics and anti-convulsant may also be prescribed. Early work has found that opioids such as morphine have an effect on the HPA axis by modulating the release of ACTH (Nikolarakis et al., 1989; Tsagarakis et al., 1989).
Although highly relevant, this area of research seems to be fairly unexplored. One study examined the effect of pain medication on HPA axis related hormones (including cortisol) in patients with chronic pain and found dramatic effects (Aloisi et al., 2011). In particular, levels of cortisol were decreased in patients using opioids or NSAIDs in comparison to controls. Levels of ACTH and levels of DHEA and DHEAS were also decreased, the latter being involved in regulating the HPA axis via anti-glucocorticoid effects and having neuroprotective properties. More importantly, hormone levels were correlated with psychological outcomes in these patients. For instance, in women, higher cortisol levels were associated with more depressive symptoms and with lower quality of life, illustrating again the interplay with psychological factors. It is unclear whether the decreased basal cortisol levels would be a direct result of medication, or chronic exposure to pain (and hence potentially to stress), or whether it may be pre-existing as a vulnerability factor. It is clear that more research needs to be done in this area (Grossman, 2019), including on how anti-depressant or anti-anxiolytic medications alter HPA axis functioning (i.e., as the HPA axis interacts with monoaminergic systems; Ulrich-Lai and Herman, 2009) as well as threat learning in the context of pain. And, it is of utmost importance to take medication into account when conducting studies into the interaction between cortisol and chronic pain.

\section{Conclusion}

Interactions between stress and pain, including between chronic stress and chronic pain, are complex and dynamic. Here, we have outlined these interactions through the lens of threat learning. We argue that threat learning is a key mechanism through which stress modulates the experience of pain and its outcomes. We provide a theoretical integration and testable hypotheses, offering suggestions for how this integration can guide future research and clinical practice.

\section{Search strategy and selection criteria}

References for this narrative review were identified by searching PubMed and Google Scholar with search terms including "pain", "chronic pain", "threat learning", "fear", "fear avoidance model", "stress", "chronic stress", "cortisol", and "HPA axis" at several stages during the writing of the initial manuscript as well as in responding to reviewer comments. We also searched reference lists of papers that were identified as particularly relevant from the PubMed search. As this is not a systematic review, we included only the most relevant articles and review papers as well as individual smaller studies that provided nuanced perspectives.

\section{Declarations of Competing Interest}

None.

\section{Acknowledgement}

This work was supported by the National Institutes of Health (1R01HD083270; PI: LE Simons).

\section{References}

Abdallah, C.G., Geha, P., 2017. Chronic pain and chronic stress: two sides of the same coin. Chronic Stress (Thousand Oaks) 1.

Abrari, K., Rashidy-Pour, A., Semnanian, S., Fathollahi, Y., 2008. Administration of corticosterone after memory reactivation disrupts subsequent retrieval of a contextual conditioned fear memory: dependence upon training intensity. Neurobiol. Learn. Mem. 89, 178-184.

Akirav, I., Maroun, M., 2007. The role of the medial prefrontal cortex-amygdala circuit in stress effects on the extinction of fear. Neural Plast. 2007, 30873.

al’Absi, M., Petersen, K.L., 2003. Blood pressure but not cortisol mediates stress effects on subsequent pain perception in healthy men and women. Pain 106, 285-295.

Albert, K., Pruessner, J., Newhouse, P., 2015. Estradiol levels modulate brain activity and 
negative responses to psychosocial stress across the menstrual cycle. Psychoneuroendocrinology 59, 14-24.

Aloisi, A.M., Buonocore, M., Merlo, L., Galandra, C., Sotgiu, A., Bacchella, L., Ungaretti, M., Demartini, L., Bonezzi, C., 2011. Chronic pain therapy and hypothalamic-pituitary-adrenal axis impairment. Psychoneuroendocrinology 36, 1032-1039.

Arntz, A., Claassens, L., 2004. The meaning of pain influences its experienced intensity. Pain 109, 20-25.

Asmundson, G.J., Coons, M.J., Taylor, S., Katz, J., 2002. PTSD and the experience of pain: research and clinical implications of shared vulnerability and mutual maintenance models. Canadian journal of psychiatry. Revue canadienne de psychiatrie 47, 930-937.

Asmundson, G.J., Katz, J., 2009. Understanding the co-occurrence of anxiety disorders and chronic pain: state-of-the-art. Depress. Anxiety 26, 888-901.

Bae, Y.J., Reinelt, J., Netto, J., Uhlig, M., Willenberg, A., Ceglarek, U., Villringer, A., Thiery, J., Gaebler, M., Kratzsch, J., 2019. Salivary cortisone, as a biomarker for psychosocial stress, is associated with state anxiety and heart rate. Psychoneuroendocrinology 101, 35-41.

Becker, S., Kleinböhl, D., Baus, D., Hölzl, R., 2011. Operant learning of perceptual sensitization and habituation is impaired in fibromyalgia patients with and without irritable bowel syndrome. Pain 152, 1408-1417.

Benson, S., Siebert, C., Koenen, L.R., Engler, H., Kleine-Borgmann, J., Bingel, U., Icenhour, A., Elsenbruch, S., 2019. Cortisol affects pain sensitivity and pain-related emotional learning in experimental visceral but not somatic pain: a randomizedcontrolled study in healthy men and women. Pain 160 (8), 1719-1728.

Bentz, D., Michael, T., Wilhelm, F.H., Hartmann, F.R., Kunz, S., von Rohr, I.R., de Quervain, D.J., 2013. Influence of stress on fear memory processes in an aversive differential conditioning paradigm in humans. Psychoneuroendocrinology 38, 1186-1197.

Biggs, E.E., Meulders, A., Kaas, A.L., Goebel, R., Vlaeyen, J.W., 2017. The acquisition and extinction of fear of painful touch: a novel tactile fear conditioning paradigm. J. Pain $18,1505-1516$.

Blundell, J., Blaiss, C.A., Lagace, D.C., Eisch, A.J., Powell, C.M., 2011. Block of glucocorticoid synthesis during re-activation inhibits extinction of an established fear memory. Neurobiol. Learn. Mem. 95, 453-460.

Borsook, D., Edwards, R., Elman, I., Becerra, L., Levine, J., 2013. Pain and analgesia: the value of salience circuits. Prog. Neurobiol. 104, 93-105.

Borsook, D., Linnman, C., Faria, V., Strassman, A.M., Becerra, L., Elman, I., 2016. Reward deficiency and anti-reward in pain chronification. Neurosci. Biobehav. Rev. 68, 282-297.

Borsook, D., Maleki, N., Becerra, L., McEwen, B., 2012. Understanding migraine through the lens of maladaptive stress responses: a model disease of allostatic load. Neuron 73, 219-234.

Bos, M.G., Schuijer, J., Lodestijn, F., Beckers, T., Kindt, M., 2014. Stress enhances reconsolidation of declarative memory. Psychoneuroendocrinology 46, 102-113.

Buchel, C., Geuter, S., Sprenger, C., Eippert, F., 2014. Placebo analgesia: a predictive coding perspective. Neuron 81, 1223-1239.

Buss, C., Davis, E.P., Shahbaba, B., Pruessner, J.C., Head, K., Sandman, C.A., 2012. Maternal cortisol over the course of pregnancy and subsequent child amygdala and hippocampus volumes and affective problems. Proc. Natl. Acad. Sci. U.S.A. 109, E1312-1319.

Caceres, C., Burns, J.W., 1997. Cardiovascular reactivity to psychological stress may enhance subsequent pain sensitivity. Pain 69, 237-244.

Cai, W.H., Blundell, J., Han, J., Greene, R.W., Powell, C.M., 2006. Postreactivation glucocorticoids impair recall of established fear memory. J. Neurosci. 26, 9560-9566.

Carpenter, L.L., Carvalho, J.P., Tyrka, A.R., Wier, L.M., Mello, A.F., Mello, M.F., Anderson, G.M., Wilkinson, C.W., Price, L.H., 2007. Decreased adrenocorticotropic hormone and cortisol responses to stress in healthy adults reporting significant childhood maltreatment. Biol. Psychiatry 62, 1080-1087.

Cathcart, S., Petkov, J., Pritchard, D., 2008. Effects of induced stress on experimental pain sensitivity in chronic tension-type headache sufferers. Eur. J. Neurol. 15, 552-558.

Catley, D., Kaell, A.T., Kirschbaum, C., Stone, A.A., 2000. A naturalistic evaluation of cortisol secretion in persons with fibromyalgia and rheumatoid arthritis. Arthritis Care Res. 13, 51-61.

Catley, M.J., O'Connell, N.E., Berryman, C., Ayhan, F.F., Moseley, G.L., 2014. Is tactile acuity altered in people with chronic pain? A systematic review and meta-analysis. J. Pain 15, 985-1000.

Cauda, F., Palermo, S., Costa, T., Torta, R., Duca, S., Vercelli, U., Geminiani, G., Torta, D.M., 2014. Gray matter alterations in chronic pain: a network-oriented meta-analytic approach. Neuroimage Clin. 4, 676-686.

Chapman, C.R., Tuckett, R.P., Song, C.W., 2008. Pain and stress in a systems perspective: reciprocal neural, endocrine, and immune interactions. J. Pain 9, 122-145.

Clark, W.C., Yang, J.C., Janal, M.N., 1986. Altered pain and visual sensitivity in humans: the effects of acute and chronic stress. Ann. N. Y. Acad. Sci. 467, 116-129.

Crettaz, B., Marziniak, M., Willeke, P., Young, P., Hellhammer, D., Stumpf, A., Burgmer, M., 2013. Stress-induced allodynia - evidence of increased pain sensitivity in healthy humans and patients with chronic pain after experimentally induced psychosocial stress. PLoS One 8, 1-7.

Crombez, G., Vlaeyen, J.W.S., Heuts, P.H., Lysens, R., 1999. Pain-related fear is more disabling than pain itself: evidence on the role of pain-related fear in chronic back pain disability. Pain 80, 329-339.

Cruz-Almeida, Y., King, C.D., Wallet, S.M., Riley 3rd, J.L., 2012. Immune biomarker response depends on choice of experimental pain stimulus in healthy adults: a preliminary study. Pain Res. Treat. 2012, 538739.

Dandolo, L.C., Schwabe, L., 2016. Stress-induced cortisol hampers memory generalization. Learn. Mem. 23, 679-683.

Danese, A., McEwen, B.S., 2012. Adverse childhood experiences, allostasis, allostatic load, and age-related disease. Physiol. Behav. 106, 29-39.

de Jong, J.R., Vlaeyen, J.W.S., Onghena, P., Cuypers, C., den Hollander, M., Ruijgrok, J., 2005. Reduction of pain-related fear in complex regional pain syndrome type I: the application of graded exposure in vivo. Pain 116, 264-275.

De Kloet, E.R., Joëls, M., Holsboer, F., 2005. Stress and the brain: from adaptation to disease. Nat. Rev. Neurosci. 6, 463-475.

de Quervain, D., Schwabe, L., Roozendaal, B., 2017. Stress, glucocorticoids and memory: implications for treating fear-related disorders. Nat. Rev. Neurosci. 18, 7-19.

de Quervain, D.J., Aerni, A., Schelling, G., Roozendaal, B., 2009. Glucocorticoids and the regulation of memory in health and disease. Front. Neuroendocrinol. 30, 358-370.

de Quervain, D.J., Bentz, D., Michael, T., Bolt, O.C., Wiederhold, B.K., Margraf, J., Wilhelm, F.H., 2011. Glucocorticoids enhance extinction-based psychotherapy. Proc. Natl. Acad. Sci. U. S. A. 108, 6621-6625.

Defrin, R., Schreiber, S., Ginzburg, K., 2015. Paradoxical pain perception in posttraumatic stress disorder: the unique role of anxiety and dissociation. J. Pain 16, 961-970.

den Hollander, M., de Jong, J.R., Volders, S., Goossens, M.E.J.B., Smeets, R.J.E.M., Vlaeyen, J.W.S., 2010. Fear reduction in patients with chronic pain: a learning theory perspective. Expert Rev. Neurother. 10, 1733-1745.

den Hollander, M., Goossens, M.E.J.B., de Jong, J.R., Ruijgrok, J., Oosterhof, J., Onghena, P., Smeets, R.J.E.M., Vlaeyen, J.W.S., 2016. Expose or protect? A randomized controlled trial of exposure in vivo versus physiotherapy in patients with Complex Regional Pain Syndrome Type 1. Pain 157, 2318-2329.

Dhabhar, F.S., 2014. Effects of stress on immune function: the good, the bad, and the beautiful. Immunol. Res. 58, 193-210.

Diamond, D.M., Campbell, A.M., Park, C.R., Halonen, J., Zoladz, P.R., 2007. The temporal dynamics model of emotional memory processing: a synthesis on the neurobiological basis of stress-induced amnesia, flashbulb and traumatic memories, and the YerkesDodson law. Neural Plast. 2007, 60803.

Dias-Ferreira, E., Sousa, J.C., Melo, I., Morgado, P., Mesquita, A.R., Cerqueira, J.J., Costa, R.M., Sousa, N., 2009. Chronic stress causes frontostriatal reorganization and affects decision-making. Science 325, 621-625.

Dickerson, S.S., Kemeny, M.E., 2004. Acute stressors and cortisol responses: a theoretical integration and synthesis of laboratory research. Psychol. Bull. 130, 355-391.

Drexler, S.M., Merz, C.J., Hamacher-Dang, T.C., Tegenthoff, M., Wolf, O.T., 2015. Effects of cortisol on reconsolidation of reactivated fear memories. Neuropsychopharmacology 40, 3036-3043.

Dufton, L.M., Konik, B., Colletti, R., Stanger, C., Boyer, M., Morrow, S., Compas, B.E., 2008. Effects of stress on pain threshold and tolerance in children with recurrent abdominal pain. Pain 136, 38-43.

Dunsmoor, J.E., Otto, A.R., Phelps, E.A., 2017. Stress promotes generalization of older but not recent threat memories. Proc. Natl. Acad. Sci. U. S. A. 114, 9218-9223.

Duthie, L., Reynolds, R.M., 2013. Changes in the maternal hypothalamic-pituitaryadrenal axis in pregnancy and postpartum: influences on maternal and fetal outcomes. Neuroendocrinology 98, 106-115.

Elsenbruch, S., Wolf, O.T., 2015. could stress contribute to pain-related fear in chronic pain? Front. Behav. Neurosci. 9.

Elvemo, N.A., Landro, N.I., Borchgrevink, P.C., Haberg, A.K., 2015. Reward responsiveness in patients with chronic pain. Eur. J. Pain 19, 1537-1543.

Fischer, S., Doerr, J.M., Strahler, J., Mewes, R., Thieme, K., Nater, U.M., 2016. Stress exacerbates pain in the everyday lives of women with fibromyalgia syndrome - the role of cortisol and alpha-amylase. Psychoneuroendocrinology 63, 68-77.

Flor, H., Grusser, S.M., 1999. Conditioned stress-induced analgesia in humans. Eur. J. Pain 3, 317-324.

Flor, H., Knost, B., Birbaumer, N., 2002. The role of operant conditioning in chronic pain: an experimental investigation. Pain 95, 111-118.

Fordyce, W.E., Fowler, R.S., Lehmann, J.F., Delateur, B.J., 1968. Some implications of learning in problems of chronic pain. J. Chron. Dis. 21, 179-190.

Garcia-Larrea, L., Peyron, R., 2013. Pain matrices and neuropathic pain matrices: a review. Pain 154 (Suppl), S29-43.

Geva, N., Pruessner, J., Defrin, R., 2014. Acute psychosocial stress reduces pain modulation capabilities in healthy men. Pain 155, 2418-2425.

Giustino, T.F., Maren, S., 2018. Noradrenergic modulation of fear conditioning and extinction. Front. Behav. Neurosci. 12, 43.

Glover, E.M., Jovanovic, T., Mercer, K.B., Kerley, K., Bradley, B., Ressler, K.J., Norrholm, S.D., 2012. Estrogen levels are associated with extinction deficits in women with posttraumatic stress disorder. Biol. Psychiatry 72, 19-24.

Graham, B.M., Milad, M.R., 2013. Blockade of estrogen by hormonal contraceptives impairs fear extinction in female rats and women. Biol. Psychiatry 73, 371-378.

Grossman, A.B., 2019. Opiates and the adrenal: the tip of the iceberg? Eur. J. Endocrinol. 180 (1), C1-C3.

Hamacher-Dang, T.C., Uengoer, M., Wolf, O.T., 2013. Stress impairs retrieval of extinguished and unextinguished associations in a predictive learning task. Neurobiol. Learn. Mem. 104, 1-8.

Hannibal, K.E., Bishop, M.D., 2014. Chronic stress, cortisol dysfunction, and pain: a psychoneuroendocrine rationale for stress management in pain rehabilitation. Phys. Ther. 94, 1816-1825.

Harnett, N.G., Ference 3rd, E.W., Wood, K.H., Wheelock, M.D., Knight, A.J., Knight, D.C., 2018. Trauma exposure acutely alters neural function during Pavlovian fear conditioning. Cortex 109, 1-13.

Hartley, C.A., Gorun, A., Reddan, M.C., Ramirez, F., Phelps, E.A., 2014. Stressor controllability modulates fear extinction in humans. Neurobiol. Learn. Mem. 113, 149-156.

Harvie, D.S., Moseley, G.L., Hillier, S.L., Meulders, A., 2017. Classical conditioning differences associated with chronic pain: a systematic review. J. Pain 18, 889-898.

Hashmi, J.A., Baliki, M.N., Huang, L., Baria, A.T., Torbey, S., Hermann, K.M., Schnitzer, T.J., Apkarian, A.V., 2013. Shape shifting pain: chronification of back pain shifts 
brain representation from nociceptive to emotional circuits. Brain 136, 2751-2768.

Heim, C., Ehlert, U., Hellhammer, D.H., 2000. The potential role of hypocortisolism in the pathophysiology of stress-related bodily disorders. Psychoneuroendocrinology 25, $1-35$.

Herman, J.P., Adams, D., Prewitt, C., 1995. Regulatory changes in neuroendocrine stressintegrative circuitry produced by a variable stress paradigm. Neuroendocrinology 61 , 180-190.

Hermans, E.J., Henckens, M.J., Joels, M., Fernandez, G., 2014. Dynamic adaptation of large-scale brain networks in response to acute stressors. Trends Neurosci. 37, 304-314.

Hermans, E.J., van Marle, H.J., Ossewaarde, L., Henckens, M.J., Qin, S., van Kesteren, M.T., Schoots, V.C., Cousijn, H., Rijpkema, M., Oostenveld, R., Fernandez, G., 2011. Stress-related noradrenergic activity prompts large-scale neural network reconfiguration. Science 334, 1151-1153.

Icenhour, A., Langhorst, J., Benson, S., Schlamann, M., Hampel, S., Engler, H., Forsting, M., Elsenbruch, S., 2015. Neural circuitry of abdominal pain-related fear learning and reinstatement in irritable bowel syndrome. Neurogastroenterol. Motil. 27, 114-127.

Imbe, H., Iwai-Liao, Y., Senba, E., 2006. Stress-induced hyperalgesia: animal models and putative mechanisms. Front. Biosci. 11, 2179-2192.

Jacobs, W.J., Nadel, L., 1985. Stress-induced recovery of fears and phobias. Psychol. Rev. 92, 512-531.

Jeitler, M., Brunnhuber, S., Meier, L., Ludtke, R., Bussing, A., Kessler, C., Michalsen, A., 2015. Effectiveness of jyoti meditation for patients with chronic neck pain and psychological distress-a randomized controlled clinical trial. J. Pain 16, 77-86.

Jenewein, J., Erni, J., Moergeli, H., Grillon, C., Schumacher, S., Mueller-Pfeiffer, C., Hassanpour, K., Seiler, A., Wittmann, L., Schnyder, U., Hasler, G., 2016. Altered pain perception and fear-learning deficits in subjects with posttraumatic stress disorder. J. Pain 17, 1325-1333.

Jensen, K., Kirsch, I., Odmalm, S., Kaptchuk, T.J., Ingvar, M., 2015. Classical conditioning of analgesic and hyperalgesic pain responses without conscious awareness. Proc. Natl. Acad. Sci. U. S. A. 112, 7863-7867.

Jessop, D.S., Turner-Cobb, J.M., 2008. Measurement and meaning of salivary cortisol: a focus on health and disease in children. Stress 11, 1-14.

Jiang, Y., Oathes, D., Hush, J., Darnall, B., Charvat, M., Mackey, S., Etkin, A., 2016. Perturbed connectivity of the amygdala and its subregions with the central executive and default mode networks in chronic pain. Pain 157, 1970-1978.

Joëls, M., Baram, T.Z., 2009. The neuro-symphony of stress. Nat. Rev. Neurosci. 10, 459-466.

Joels, M., Fernandez, G., Roozendaal, B., 2011. Stress and emotional memory: a matter of timing. Trends Cogn. Sci. 15, 280-288.

Joels, M., Karst, H., DeRijk, R., de Kloet, E.R., 2008. The coming out of the brain mineralocorticoid receptor. Trends Neurosci. 31, 1-7.

Joels, M., Pu, Z., Wiegert, O., Oitzl, M.S., Krugers, H.J., 2006. Learning under stress: how does it work? Trends Cogn. Sci. 10, 152-158.

Jones, G.T., Power, C., Macfarlane, G.J., 2009. Adverse events in childhood and chronic widespread pain in adult life: results from the 1958 British Birth Cohort Study. Pain 143, 92-96.

Karos, K., Williams, A.C.C., Meulders, A., Vlaeyen, J.W.S., 2018. Pain as a threat to the social self: a motivational account. Pain 159, 1690-1695.

Kensinger, E.A., 2004. Remembering emotional experiences: the contribution of valence and arousal. Rev. Neurosci. 15, 241-251.

Kirschbaum, C., Pirke, K.M., Hellhammer, D.H., 1993. The 'Trier Social Stress Test'-a tool for investigating psychobiological stress responses in a laboratory setting. Neuropsychobiology 28, 76-81.

Klinger, R., Matter, N., Kothe, R., Dahme, B., Hofmann, U.G., Krug, F., 2010. Unconditioned and conditioned muscular responses in patients with chronic back pain and chronic tension-type headaches and in healthy controls. Pain 150, 66-74.

Kluen, L.M., Agorastos, A., Wiedemann, K., Schwabe, L., 2017a. Noradrenergic stimulation impairs memory generalization in women. J. Cogn. Neurosci. 29, 1279-1291.

Kluen, L.M., Nixon, P., Agorastos, A., Wiedemann, K., Schwabe, L., 2017b. Impact of stress and glucocorticoids on schema-based learning. Neuropsychopharmacology 42, 1254-1261.

Kucyi, A., Davis, K.D., 2015. The dynamic pain connectome. Trends Neurosci. 38, 86-95.

Kudielka, B.M., Hellhammer, D.H., Wust, S., 2009. Why do we respond so differently? Reviewing determinants of human salivary cortisol responses to challenge. Psychoneuroendocrinology 34, 2-18.

Labus, J.S., Hubbard, C.S., Bueller, J., Ebrat, B., Tillisch, K., Chen, M., Stains, J., Dukes, G.E., Kelleher, D.L., Naliboff, B.D., Fanselow, M., Mayer, E.A., 2013. Impaired emotional learning and involvement of the corticotropin-releasing factor signaling system in patients with irritable bowel syndrome. Gastroenterology 145, 1253-1261 e1251-1253.

Lass-Hennemann, J., Michael, T., 2014. Endogenous cortisol levels influence exposure therapy in spider phobia. Behav. Res. Ther. 60, 39-45.

Leeuw, M., Goossens, M.E.J.B., van Breukelen, G.J.P., de Jong, J.R., Heuts, P.H.T.G., Smeets, R.J.E.M., Köke, A.J., Vlaeyen, J.W.S., 2008. Exposure in vivo versus operant graded activity in chronic low back pain patients: results of a randomized controlled trial. Pain 138, 192-207.

Li, S., Graham, B.M., 2016. Estradiol is associated with altered cognitive and physiological responses during fear conditioning and extinction in healthy and spider phobic women. Behav. Neurosci. 130, 614-623.

Lopez-Martinez, A.E., Ramirez-Maestre, C., Esteve, R., 2014. An examination of the structural link between post-traumatic stress symptoms and chronic pain in the framework of fear-avoidance models. Eur. J. Pain 18, 1129-1138.

Lopez-Sola, M., Koban, L., Wager, T.D., 2018. Transforming pain with prosocial meaning: a functional magnetic resonance imaging study. Psychosom. Med. 80, 814-825.

Lorenz, J., Minoshima, S., Casey, K.L., 2003. Keeping pain out of mind: the role of the dorsolateral prefrontal cortex in pain modulation. Brain 126, 1079-1091.

Lovibond, P.F., Mitchell, C.J., Minard, E., Brady, A., Menzies, R.G., 2009. Safety behaviours preserve threat beliefs: protection from extinction of human fear conditioning by an avoidance response. Behav. Res. Ther. 47, 716-720.

Madden, V.J., Harvie, D.S., Parker, R., Jensen, K.B., Vlaeyen, J.W., Moseley, G.L., Stanton, T.R., 2015. Can pain or hyperalgesia be a classically conditioned response in humans? A systematic review and meta-analysis. Pain Med. 17, 1094-1111.

Maddox, S.A., Hartmann, J., Ross, R.A., Ressler, K.J., 2019. Deconstructing the gestalt: mechanisms of fear, threat, and trauma memory encoding. Neuron 102, 60-74.

Magarinos, A.M., McEwen, B.S., 1995. Stress-induced atrophy of apical dendrites of hippocampal CA3c neurons: involvement of glucocorticoid secretion and excitatory amino acid receptors. Neuroscience 69, 89-98.

Maier, S.F., 2003. Bi-directional immune-brain communication: implications for understanding stress, pain, and cognition. Brain Behav. Immun. 17, 69-85.

McBeth, J., Chiu, Y.H., Silman, A.J., Ray, D., Morriss, R., Dickens, C., Gupta, A., Macfarlane, G.J., 2005. Hypothalamic-pituitary-adrenal stress axis function and the relationship with chronic widespread pain and its antecedents. Arthritis Res. Ther. 7, R992-r1000.

McEwen, B.S., 1998. Stress, adaptation, and disease. Allostasis and allostatic load. Ann. N. Y. Acad. Sci. 840, 33-44.

McEwen, B.S., 2008. Central effects of stress hormones in health and disease: understanding the protective and damaging effects of stress and stress mediators. Eur. J. Pharmacol. 583, 174-185.

McLaughlin, K.A., Koenen, K.C., Bromet, E.J., Karam, E.G., Liu, H., Petukhova, M., Ruscio, A.M., Sampson, N.A., Stein, D.J., Aguilar-Gaxiola, S., Alonso, J., Borges, G., Demyttenaere, K., Dinolova, R.V., Ferry, F., Florescu, S., de Girolamo, G., Gureje, O., Kawakami, N., Lee, S., Navarro-Mateu, F., Piazza, M., Pennell, B.E., Posada-Villa, J., Ten Have, M., Viana, M.C., Kessler, R.C., 2017. Childhood adversities and posttraumatic stress disorder: evidence for stress sensitisation in the World Mental Health Surveys. Br. J. Psychiatry 211, 280-288.

McLean, S.A., Williams, D.A., Harris, R.E., Kop, W.J., Groner, K.H., Ambrose, K., Lyden, A.K., Gracely, R.H., Crofford, L.J., Geisser, M.E., Sen, A., Biswas, P., Clauw, D.J., 2005. Momentary relationship between cortisol secretion and symptoms in patients with fibromyalgia. Arthritis Rheum. 52, 3660-3669.

Meeus, M., van Oosterwijck, J., Ickmans, K., Baert, I., Coppieters, I., Roussel, N., Struyf, F., Pattyn, N., Nijs, J., 2015. Interrelationships between pain processing, cortisol and cognitive performance in chronic whiplash-associated disorders. Clin. Rheumatol. 34, $545-553$.

Meir Drexler, S., Wolf, O.T., 2017. Stress disrupts the reconsolidation of fear memories in men. Psychoneuroendocrinology 77, 95-104.

Merz, C.J., Hamacher-Dang, T.C., Wolf, O.T., 2014. Exposure to stress attenuates fear retrieval in healthy men. Psychoneuroendocrinology 41, 89-96.

Merz, C.J., Tabbert, K., Schweckendiek, J., Klucken, T., Vaitl, D., Stark, R., Wolf, O.T., 2012. Oral contraceptive usage alters the effects of cortisol on implicit fear learning. Horm. Behav. 62, 531-538.

Merz, C.J., Wolf, O.T., Schweckendiek, J., Klucken, T., Vaitl, D., Stark, R., 2013. Stress differentially affects fear conditioning in men and women. Psychoneuroendocrinology 38, 2529-2541.

Metikaridis, T.D., Hadjipavlou, A., Artemiadis, A., Chrousos, G., Darviri, C., 2016. Effect of a stress management program on subjects with neck pain: A pilot randomized controlled trial. Journal of back and musculoskeletal rehabilitation.

Meulders, A., Franssen, M., Fonteyne, R., Vlaeyen, J.W., 2016. Acquisition and extinction of operant pain-related avoidance behavior using a 3 degrees-of-freedom robotic arm. Pain 157, 1094-1104.

Meulders, A., Harvie, D.S., Bowering, J.K., Caragianis, S., Vlaeyen, J.W., Moseley, G.L., 2014. Contingency learning deficits and generalization in chronic unilateral hand pain patients. J. Pain 15, 1046-1056.

Meulders, A., Jans, A., Vlaeyen, J.W., 2015. Differences in pain-related fear acquisition and generalization: an experimental study comparing patients with fibromyalgia and healthy controls. Pain 156, 108-122.

Meulders, A., Meulders, M., Stouten, I., De Bie, J., Vlaeyen, J.W., 2017. Extinction of fear generalization: a comparison between fibromyalgia patients and healthy control participants. J. Pain 18, 79-95.

Meulders, A., Vlaeyen, J.W., 2012. Reduction of fear of movement-related pain and painrelated anxiety: an associative learning approach using a voluntary movement paradigm. Pain 153, 1504-1513.

Meulders, A., Vlaeyen, J.W., 2013. The acquisition and generalization of cued and contextual pain-related fear: an experimental study using a voluntary movement paradigm. Pain 154, 272-282.

Meuret, A.E., Trueba, A.F., Abelson, J.L., Liberzon, I., Auchus, R., Bhaskara, L., Ritz, T., Rosenfield, D., 2015. High cortisol awakening response and cortisol levels moderate exposure-based psychotherapy success. Psychoneuroendocrinology 51, 331-340.

Miller, G.E., Chen, E., Zhou, E.S., 2007. If it goes up, must it come down? Chronic stress and the hypothalamic-pituitary-adrenocortical axis in humans. Psychol. Bull. 133, 25-45.

Miller, R., Plessow, F., Kirschbaum, C., Stalder, T, 2013. Classification criteria for distinguishing cortisol responders from nonresponders to psychosocial stress: evaluation of salivary cortisol pulse detection in panel designs. Psychosom. Med. 75, 832-840.

Miller, R., Stalder, T., Jarczok, M., Almeida, D.M., Badrick, E., Bartels, M., Boomsma, D.I., Coe, C.L., Dekker, M.C.J., Donzella, B., Fischer, J.E., Gunnar, M.R., Kumari, M., Lederbogen, F., Power, C., Ryff, C.D., Subramanian, S.V., Tiemeier, H., Watamura, S.E., Kirschbaum, C., 2016. The CIRCORT database: Reference ranges and seasonal changes in diurnal salivary cortisol derived from a meta-dataset comprised of 15 field studies. Psychoneuroendocrinology 73, 16-23.

Miracle, A.D., Brace, M.F., Huyck, K.D., Singler, S.A., Wellman, C.L., 2006. Chronic stress impairs recall of extinction of conditioned fear. Neurobiol. Learn. Mem. 85, 213-218. 
Moseley, G.L., Butler, D.S., 2015. Fifteen years of explaining pain: the past, present, and future. J. Pain 16, 807-813.

Moseley, G.L., Vlaeyen, J.W.S., 2015. Beyond nociception : the imprecision hypothesis of chronic pain. Pain 156, 35-38.

Moustafa, A.A., Gilbertson, M.W., Orr, S.P., Herzallah, M.M., Servatius, R.J., Myers, C.E., 2013. A model of amygdala-hippocampal-prefrontal interaction in fear conditioning and extinction in animals. Brain Cogn. 81, 29-43.

Muhtz, C., Rodriguez-Raecke, R., Hinkelmann, K., Moeller-bertram, T., Kiefer, F., Wiedemann, K., May, A., Otte, C., 2013. Cortisol response to experimental pain in patients with chronic low back pain and patients with major depression. Pain Med. 14, 498-503.

Mutso, A.A., Radzicki, D., Baliki, M.N., Huang, L., Banisadr, G., Centeno, M.V., Radulovic, J., Martina, M., Miller, R.J., Apkarian, A.V., 2012. Abnormalities in hippocampal functioning with persistent pain. J. Neurosci. 32, 5747-5756.

Nader, K., Hardt, O., 2009. A single standard for memory: the case for reconsolidation. Nat. Rev. Neurosci. 10, 224-234.

Navratilova, E., Morimura, K., Xie, J.Y., Atcherley, C.W., Ossipov, M.H., Porreca, F., 2016. Positive emotions and brain reward circuits in chronic pain. J. Comp. Neurol. 524, 1646-1652.

Navratilova, E., Porreca, F., 2014. Reward and motivation in pain and pain relief. Nat. Neurosci. 17, 1304-1312.

Nees, F., Becker, S., 2018. Psychological processes in chronic pain: influences of reward and fear learning as key mechanisms-behavioral evidence, neural circuits, and maladaptive changes. Neuroscience 387, 72-84.

Nees, F., Loffler, M., Usai, K., Flor, H., 2019. Hypothalamic-pituitary-adrenal axis feedback sensitivity in different states of back pain. Psychoneuroendocrinology 101, 60-66.

Neigh, G.N., Ali, F.F., 2016. Co-morbidity of PTSD and immune system dysfunction: opportunities for treatment. Curr. Opin. Pharmacol. 29, 104-110.

Nelson, S.M., Cunningham, N.R., Kashikar-Zuck, S., 2017. A conceptual framework for understanding the role of adverse childhood experiences in pediatric chronic pain. Clin. J. Pain 33, 264-270.

Neugebauer, V., Li, W., Bird, G.C., Han, J.S., 2004. The amygdala and persistent pain. Neuroscientist 10, 221-234.

Neville, A., Soltani, S., Pavlova, M., Noel, M., 2018. Unravelling the relationship between parent and child PTSD and pediatric chronic pain: the mediating role of pain catastrophizing. J. Pain 19, 196-206.

Nicholas, M., Vlaeyen, J.W.S., Rief, W., Barke, A., Aziz, Q., Benoliel, R., Cohen, M., Evers, S., Giamberardino, M.A., Goebel, A., Korwisi, B., Perrot, S., Svensson, P., Wang, S.J., Treede, R.D., Pain, I.T.f.t.C.o.C, 2019. The IASP classification of chronic pain for ICD11: chronic primary pain. Pain 160, 28-37.

Nikolarakis, K.E., Pfeiffer, A., Stalla, G.K., Herz, A., 1989. Facilitation of ACTH secretion by morphine is mediated by activation of CRF releasing neurons and sympathetic neuronal pathways. Brain Res. 498, 385-388.

Noel, M., Wilson, A.C., Holley, A.L., Durkin, L., Patton, M., Palermo, T.M., 2016. Posttraumatic stress disorder symptoms in youth with vs without chronic pain. Pain 157, 2277-2284.

Oh, D.L., Jerman, P., Silverio Marques, S., Koita, K., Purewal Boparai, S.K., Burke Harris, N., Bucci, M., 2018. Systematic review of pediatric health outcomes associated with childhood adversity. BMC Pediatr. 18, 83.

Pace, T.W., Heim, C.M., 2011. A short review on the psychoneuroimmunology of posttraumatic stress disorder: from risk factors to medical comorbidities. Brain Behav. Immun. 25, 6-13.

Palmer, F.B., Anand, K.J., Graff, J.C., Murphy, L.E., Qu, Y., Volgyi, E., Rovnaghi, C.R., Moore, A., Tran, Q.T., Tylavsky, F.A., 2013. Early adversity, socioemotional development, and stress in urban 1-year-old children. J. Pediatr. 163, 1733-1739 e1731.

Phelps, E.A., Delgado, M.R., Nearing, K.I., LeDoux, J.E., 2004. Extinction learning in humans: role of the amygdala and vmPFC. Neuron 43, 897-905.

Ploghaus, A., Narain, C., Beckmann, C.F., Clare, S., Bantick, S., Wise, R.G., Matthews, P.M., Rawlins, J.N., Tracey, I., 2001. Exacerbation of pain by anxiety is associated with activity in a hippocampal network. J. Neurosci. 21, 9896-9903.

Quaedflieg, C., Stoffregen, H., Sebalo, I., Smeets, T., 2019. Stress-induced impairment in goal-directed instrumental behaviour is moderated by baseline working memory. Neurobiol. Learn. Mem. 158, 42-49.

Quaedflieg, C.W.E.M., Schwabe, L., 2018. Memory dynamics under stress. Memory 26, 364-376.

Quaedflieg, C.W.E.M., Schwabe, L., Meyer, T., Smeets, T., 2013. Time dependent effects of stress prior to encoding on event-related potentials and $24 \mathrm{~h}$ delayed retrieval. Psychoneuroendocrinology 38, 3057-3069.

Quaedflieg, C.W.E.M., van de Ven, V., Meyer, T., Siep, N., Merckelbach, H., Smeets, T., 2015. Temporal dynamics of stress-induced alternations of intrinsic amygdala connectivity and neuroendocrine levels. PLoS One 10, e0124141.

Quirk, G.J., Mueller, D., 2008. Neural mechanisms of extinction learning and retrieval. Neuropsychopharmacology 33, 56-72.

Radley, J., Morilak, D., Viau, V., Campeau, S., 2015. Chronic stress and brain plasticity: mechanisms underlying adaptive and maladaptive changes and implications for stress-related CNS disorders. Neurosci. Biobehav. Rev. 58, 79-91.

Radley, J.J., Rocher, A.B., Rodriguez, A., Ehlenberger, D.B., Dammann, M., McEwen, B.S., Morrison, J.H., Wearne, S.L., Hof, P.R., 2008. Repeated stress alters dendritic spine morphology in the rat medial prefrontal cortex. J. Comp. Neurol. 507, 1141-1150.

Raeder, F., Merz, C.J., Tegenthoff, M., Wolf, O.T., Margraf, J., Zlomuzica, A., 2019. Postexposure cortisol administration does not augment the success of exposure therapy: a randomized placebo-controlled study. Psychoneuroendocrinology 99, 174-182.

Raio, C.M., Brignoni-Perez, E., Goldman, R., Phelps, E.A., 2014. Acute stress impairs the retrieval of extinction memory in humans. Neurobiol. Learn. Mem. 112, 212-221.

Raio, C.M., Hartley, C.A., Orederu, T.A., Li, J., Phelps, E.A., 2017. Stress attenuates the flexible updating of aversive value. Proc. Natl. Acad. Sci. U. S. A. 114, 11241-11246.

Raio, C.M., Phelps, E.A., 2015. The influence of acute stress on the regulation of conditioned fear. Neurobiol. Stress 1, 134-146.

Reinhardt, T., Kleindienst, N., Treede, R., Bohus, M., Schmahl, C., 2013. Individual modulation of pain sensitivity. Main Med. 14, 676-685.

Ren, K., Dubner, R., 2010. Interactions between the immune and nervous systems in pain. Nat. Med. 16, 1267-1276.

Rivat, C., Laboureyras, E., Laulin, J., Le Roy, C., Richebe, P., Simonnet, G., 2007. Nonnociceptive environmental stress induces hyperalgesia, not analgesia, in pain and opioid-experienced rats. Neuropsychopharmacology 32, 2217-2228.

Roquet, R.F., Monfils, M.H., 2018. Does exercise augment operant and Pavlovian extinction: a meta-analysis. J. Psychiatr. Res. 96, 73-93.

Schiller, D., Kanen, J.W., LeDoux, J.E., Monfils, M.H., Phelps, E.A., 2013. Extinction during reconsolidation of threat memory diminishes prefrontal cortex involvement. Proc. Natl. Acad. Sci. U. S. A. 110, 20040-20045.

Schneider, C., Palomba, D., Flor, H., 2004. Pavlovian conditioning of muscular responses in chronic pain patients: central and peripheral correlates. Pain 112, 239-247.

Schwabe, L., 2017. Memory under stress: from single systems to network changes. Eur. J. Neurosci. 45, 478-489.

Schwabe, L., Joels, M., Roozendaal, B., Wolf, O.T., Oitzl, M.S., 2012. Stress effects on memory: an update and integration. Neurosci. Biobehav. Rev. 36, 1740-1749.

Schwabe, L., Wolf, O.T., 2010. Stress impairs the reconsolidation of autobiographical memories. Neurobiol. Learn. Mem. 94, 153-157.

Schwabe, L., Wolf, O.T., 2011. Stress-induced modulation of instrumental behavior: from goal-directed to habitual control of action. Behav. Brain Res. 219, 321-328.

Schweinhardt, P., Bushnell, M.C., 2010. Pain imaging in health and disease - how far have we come? J. Clin. Invest. 120, 3788-3797.

Segerstrom, S.C., Miller, G.E., 2004. Psychological stress and the human immune system: a meta-analytic study of 30 years of inquiry. Psychol. Bull. 130, 601-630.

Seminowicz, D.A., Moayedi, M., 2017. The dorsolateral prefrontal cortex in acute and chronic pain. J. Pain 18, 1027-1035.

Sharp, T.J., Harvey, A.G., 2001. Chronic pain and posttraumatic stress disorder: mutual maintenance? Clin. Psychol. Rev. 21, 857-877.

Simons, L.E., Elman, I., Borsook, D., 2014a. Psychological processing in chronic pain: a neural systems approach. Neurosci. Biobehav. Rev. 39, 61-78.

Simons, L.E., Erpelding, N., Hernandez, J.M., Serrano, P., Zhang, K., Lebel, A.A., Sethna, N., BErde, C.B., Prabhu, S.P., Becerra, L., Borsook, D., 2016. Fear and reward circuit alterations in pediatric CRPS. Front. Hum. Neurosci. 9, 703.

Simons, L.E., Pielech, M., Erpelding, N., Linnman, C., Moulton, E., Sava, S., Lebel, a., Serrano, P., Sethna, N., Berde, C., Becerra, L., Borsook, D., 2014b. The responsive amygdala: treatment-induced alterations in functional connectivity in pediatric complex regional pain syndrome. Pain.

Slominski, R., Rovnaghi, C.R., Anand, K.J., 2015. Methodological considerations for hair cortisol measurements in children. Ther. Drug Monit. 37, 812-820.

Smeets, T., Cornelisse, S., Quaedflieg, C.W.E.M., Meyer, T., Jelicic, M., Merckelbach, H., 2012. Introducing the Maastricht Acute Stress Test (MAST): a quick and non-invasive approach to elicit robust autonomic and glucocorticoid stress responses. Psychoneuroendocrinology 37, 1998-2008.

Smeets, T., van Ruitenbeek, P., Hartogsveld, B., Quaedflieg, C., 2019. Stress-induced reliance on habitual behavior is moderated by cortisol reactivity. Brain Cogn. 133, 60-71.

Soravia, L.M., Heinrichs, M., Winzeler, L., Fisler, M., Schmitt, W., Horn, H., Dierks, T., Strik, W., Hofmann, S.G., de Quervain, D.J., 2014. Glucocorticoids enhance in vivo exposure-based therapy of spider phobia. Depress. Anxiety 31, 429-435.

Sripada, R.K., Swain, J.E., Evans, G.W., Welsh, R.C., Liberzon, I., 2014. Childhood poverty and stress reactivity are associated with aberrant functional connectivity in default mode network. Neuropsychopharmacology 39, 2244-2251.

Strahler, J., Skoluda, N., Kappert, M.B., Nater, U.M., 2017. Simultaneous measurement of salivary cortisol and alpha-amylase: application and recommendations. Neurosci. Biobehav. Rev. 83, 657-677.

Sveinsdottir, V., Eriksen, H.R., Ursin, H., Hansen, A.M., Harris, A., 2016. Cortisol, health, and coping in patients with nonspecific low back pain. Appl. Psychophysiol. Biofeedback 41, 9-16.

Terman, G.W., Shavit, Y., Lewis, J.W., Cannon, J.T., Liebeskind, J.C., 1984. Intrinsic mechanisms of pain inhibition: activation by stress. Science 226, 1270-1277.

Timmers, I., Kaas, A.L., Quaedflieg, C.W., Biggs, E.E., Smeets, T., de Jong, J.R., 2018. Fear of pain and cortisol reactivity predict the strength of stress-induced hypoalgesia. Eur. J. Pain 22 (7), 1291-1303.

Totsch, S.K., Sorge, R.E., 2017. Immune system involvement in specific pain conditions. Mol. Pain 13, 1744806917724559.

Tracey, I., 2010. Getting the pain you expect: mechanisms of placebo, nocebo and reappraisal effects in humans. Nat. Med. 16, 1277-1283.

Tsagarakis, S., Navarra, P., Rees, L.H., Besser, M., Grossman, A., Navara, P., 1989. Morphine directly modulates the release of stimulated corticotrophin-releasing factor-41 from rat hypothalamus in vitro. Endocrinology 124, 2330-2335.

Uceyler, N., Valenza, R., Stock, M., Schedel, R., Sprotte, G., Sommer, C., 2006. Reduced levels of antiinflammatory cytokines in patients with chronic widespread pain. Arthritis Rheum. 54, 2656-2664.

Ulrich-Lai, Y.M., Herman, J.P., 2009. Neural regulation of endocrine and autonomic stress responses. Nat. Rev. Neurosci. 10, 397-409.

Vachon-Presseau, E., 2018. Effects of stress on the corticolimbic system: implications for chronic pain. Prog. Neuropsychopharmacol. Biol. Psychiatry 87 (Pt B), 216-223.

Vachon-Presseau, E., Martel, M., Roy, M., Caron, E., Albouy, G., Marin, M., Plante, I., Sullivan, M.J., Lupien, S.J., Rainville, P., 2013a. Acute stress contributes to individual differences in pain and pain-related brain activity in healthy and chronic pain patients. J. Neurosci. 33, 6826-6833. 
Vachon-Presseau, E., Roy, M., Martel, M., Caron, E., Marin, M., Chen, J., Albouy, G., Plante, I., Sullivan, M.J., Lupien, S.J., Rainville, P., 2013b. The stress model of chronic pain: evidence from basal cortisol and hippocampal structure and function in humans. Brain 136, 815-827.

Van Cauter, E., Refetoff, S., 1985. Evidence for two subtypes of Cushing's disease based on the analysis of episodic cortisol secretion. N. Engl. J. Med. 312, 1343-1349.

van Oort, J., Tendolkar, I., Hermans, E.J., Mulders, P.C., Beckmann, C.F., Schene, A.H. Fernandez, G., van Eijndhoven, P.F., 2017. How the brain connects in response to acute stress: a review at the human brain systems level. Neurosci. Biobehav. Rev. 83, 281-297.

Van Uum, S.H.M., Sauvé, B., Fraser, L.A., Morley-Forster, P., Paul, T.L., Koren, G., 2008. Elevated content of cortisol in hair of patients with severe chronic pain : a nove biomarker for stress. Stress 11, 483-488.

van Vliet, C.M., Meulders, A., Vancleef, L.M.G., Vlaeyen, J.W.S., 2018. The opportunity to avoid pain may paradoxically increase fear. J. Pain 19 (10), 1222-1230.

Villemure, C., Bushnell, M.C., 2002. Cognitive modulation of pain: how do attention and emotion influence pain processing? Pain 95, 195-199.

Vinall, J., Pavlova, M., Asmundson, G.J., Rasic, N., Noel, M., 2016. Mental health comorbidities in pediatric chronic pain: a narrative review of epidemiology, models, neurobiological mechanisms and treatmen. Children (Basel) 3.

Vlaeyen, J.W., Crombez, G., Linton, S.J., 2016. The fear-avoidance model of pain. Pain 157, 1588-1589.

Vlaeyen, J.W., Kole-Snijders, A.M., Boeren, R.G., van Eek, H., 1995a. Fear of movement/ (re)injury in chronic low back pain and its relation to behavioral performance. Pain $62,363-372$.

Vlaeyen, J.W.S., Kole-Snijders, A.M., Rotteveel, A.M., Ruesink, R., Heuts, P.H., 1995b. The role of fear of movement/(re)injury in pain disability. J. Occup. Rehabil. 5,
235-252.

Volders, S., Meulders, A., De Peuter, S., Vervliet, B., Vlaeyen, J.W., 2012. Safety behavio can hamper the extinction of fear of movement-related pain: an experimental investigation in healthy participants. Behav. Res. Ther. 50, 735-746.

Wager, T.D., Atlas, L.Y., Lindquist, Ma, Roy, M., Woo, C.-W., Kross, E., 2013. An fMRIbased neurologic signature of physical pain. New England J. Med. Surg. Collat. Branches Sci. 368, 1388-1397.

Weger, M., Sandi, C., 2018. High anxiety trait: a vulnerable phenotype for stress-induced depression. Neurosci. Biobehav. Rev. 87, 27-37.

Wilber, A.A., Walker, A.G., Southwood, C.J., Farrell, M.R., Lin, G.L., Rebec, G.V., Wellman, C.L., 2011. Chronic stress alters neural activity in medial prefrontal cortex during retrieval of extinction. Neuroscience 174, 115-131.

Williams, A.C.D.C., Craig, K.D., 2016. Updating the definition of pain. Pain 157 , $2420-2423$.

Woda, A., Picard, P., Dutheil, F., 2016. Dysfunctional stress responses in chronic pain. Psychoneuroendocrinology 71, 127-135.

Wood, K.H., Wheelock, M.D., Shumen, J.R., Bowen, K.H., Ver Hoef, L.W., Knight, D.C., 2015. Controllability modulates the neural response to predictable but not unpredictable threat in humans. Neuroimage 119, 371-381.

Zale, E.L., Lange, K.L., Fields, S.A., Ditre, J.W., 2013. The relation between pain-related fear and disability: a meta-analysis. J. Pain 14, 1019-1030.

Zaman, J., Vlaeyen, J.W.S., Van Oudenhove, L., Wiech, K., Van Diest, I., 2015. Associative fear learning and perceptual discrimination: a perceptual pathway in the development of chronic pain. Neurosci. Biobehav. Rev. 51, 118-125.

Zankert, S., Bellingrath, S., Wust, S., Kudielka, B.M., 2019. HPA axis responses to psychological challenge linking stress and disease: What do we know on sources of intraand interindividual variability? Psychoneuroendocrinology 105, 86-97. 